\title{
Identification of everyday objects on the basis of silhouette and outline versions
}

\author{
Johan Wagemans, Joeri De Winter, Hans Op de Beeck\#, Annemie Ploeger $\uparrow$, \\ Tom Beckers\#, Peter Vanroose§ \\ Department of Psychology, University of Leuven, Tiensestraat 102, B 3000 Leuven, Belgium; \\ e-mail: johan.wagemans@psy.kuleuven.be; Department of Psychology, University of Amsterdam, \\ Amsterdam, The Netherlands; § Department of Electrical Engineering, ESAT-PSI-VISICS, University \\ of Leuven, Leuven, Belgium; \# also Research Foundation - Flanders, Belgium [FWO] \\ Received 25 May 2007, in revised form 18 September 2007; published online 22 February 2008
}

\begin{abstract}
Line drawings of everyday objects were modified into silhouettes by filling-in the complete area enclosed by boundary contours, and outline versions were created by extracting the contours from the silhouettes. A large number of participants was asked to try to identify these silhouette and outline versions in experiment 1 . Identifiability ranged from $0 \%$ to $100 \%$ correct responses with a large range in-between. Several kinds of errors and several reasons for difficulties with identification emerged in our data set. In experiment 2, we compared the original identification rates to those of inverted silhouettes (white figures on a black background), and in experiment 3 we compared the original identification rates of objects with filled-in holes or background parts to those of versions without filling-in. These stimuli and identification norms are useful for additional research on priming and context effects of object identification, neuropsychological deficits of object identification, and all kinds of studies with silhouettes where the role of top down knowledge could be of interest.
\end{abstract}

\section{Introduction}

Line drawings of everyday objects are generally very easy to identify, perhaps even as easy as the original objects themselves, which shows that the most essential information about object identity is preserved (or even enhanced) in line drawings (Biederman 1987; Biederman and Ju 1988; Koenderink and van Doorn 1982). Moreover, cave art, cartoons, and comic books go one step further in demonstrating that the lines do not have to capture the edges defined by luminance or colour contrast very accurately to reveal a particular prehistoric animal or political figure. Cave art has attracted the attention of perception researchers mainly for this reason (Gerr 1982; Kennedy and Silver 1974; Wade 2006; Wade and Melcher 2006). Combined image-processing and psychophysical research has shown that line drawings are indeed much more informative than the edges extracted from grey-level photographs (Sanocki et al 1998). The best artists can extract the essence of an object's shape or a person's facial characteristics from the rich sources of visual information in natural viewing conditions or in highquality photographs and express these in a few lines on a flat surface like a piece of paper. The fact that this process works so well suggests that this kind of information (ie a few high-contrast, curved lines) triggers the kind of machinery that the visual system has developed (phylogenetically and/or ontogenetically) to extract information about object shape and identity from the visual stimulation that is available in natural viewing conditions (Braje et al 1995; Koenderink et al 1996).

It is for all these reasons that line drawings of everyday objects have become a widely used type of stimulus in experimental research on object identification and picture naming. Snodgrass and Vanderwart (1980) have given a strong additional impetus to this kind of research by providing a set of 260 line drawings with published norms for name agreement, familiarity, complexity, etc, which has been very instrumental in comparing results on picture naming, object identification, priming, etc across studies. 
Response times and developmental norms have since been provided too (Cycowicz et al 1997; Snodgrass and Yuditsky 1996), and other researchers have created coloured and grey-scale renderings of the Snodgrass and Vanderwart set (Rossion and Pourtois 2004).

Rather than enriching the stimuli by adding shading and colour to the Snodgrass and Vanderwart stimulus set or providing multiple exemplars of each object category (Op de Beeck and Wagemans 2001), we have embarked upon an extensive research programme aimed at a better understanding of the necessary and sufficient conditions for shape-based object identification by eliminating certain aspects from the line drawings and enhancing others. More specifically, in this research programme we are mainly interested in the role of contours and their curvature singularities in shape and object perception (for a review, see De Winter and Wagemans 2004). An important source of inspiration has been Attneave's (1954) claim that curvature extrema (points along the contour where positive curvature reaches its maximum and negative curvature reaches its minimum) are most important for shape, a claim that has recently been supported by an information-theoretic analysis (Feldman and Singh 2005) as well as by empirical results (Norman et al 2001).

Our research programme so far consists of five different but related lines of research. First, we have performed a segmentation study with outlines derived from the Snodgrass and Vanderwart set to test well-known geometric rules for shape segmentation in a large set of stimuli with a large number of observers (De Winter and Wagemans 2006), showing their validity, relative strength, and interplay, as well as discovering some new principles. One of these rules, the minima rule (Hoffman and Richards 1984), states that objects are segmented into parts where the contour contains pairs of negative minima or deep concavities, and forms the basis of an influential theory of shape-based object recognition, recognition-by-components or RBC theory (Biederman 1987; but see also Kurbat 1994). Hence, there is an intricate connection between curvature singularities, shape segmentation, and object identification. Second, we have investigated which points along the contour are most salient by asking observers to mark points and then analysing these markings in a large number of ways, using different smoothing levels and thresholds, and relating the results to local, semi-local, and global shape factors (De Winter and Wagemans 2008a). Third, we have extracted curvature singularities and other salient points from the contours and connected them by straight lines, preserving the connectivity but removing the continuous curvature of normal contours, and we have tested identifiability of these straight-line versions in large subject samples (De Winter and Wagemans 2008b). This study allowed a formal, quantitative examination of an informal demonstration by Attneave (1954), which is known as Attneave's sleeping cat (see also Norman et al 2001). Fourth, we have tested the role of curvature singularities for object identification in another, complementary way by presenting fragments of different lengths around them, using different conditions to place the fragments, different fragmentation levels, and a long presentation time (Panis et al 2008a), as well as multiple brief exposures (Panis and Wagemans 2008). Interesting differences with the straight-line study emerged because fragments around salient points proved to be less informative than fragments around points midway between salient points (see also Kennedy and Domander 1985), which we explained by referring to the role of perceptual grouping in studies with fragmented pictures. Fifth, we have also begun to explore the interrelations between perceptual grouping and object identification more systematically by placing Gabor patches on the contour or in the surface of these object outlines and asking for detection, discrimination, and more global shape perception as a function of contour alignment and identifiability (Bleumers et al 2007; Nygård and Wagemans 2005). 
The starting point of all these studies was the conversion of the line drawings from Snodgrass and Vanderwart (1980) into outline versions. To this end, we scanned all the stimuli and made silhouette versions of them by blackening the whole area surrounded by the boundary contours. ${ }^{(1)}$ We then extracted the edges of these silhouettes and turned them into smooth, curved, closed outlines by spline-fitting them. This process provided us with 260 silhouette and outline versions of the Snodgrass and Vanderwart set, with variable levels of identifiability and continuous curvature values along the contours (the singularities of which could then be easily extracted and used in these further studies). In this paper we report all the details of an extensive study with these silhouettes and outlines. (A summary has been included as Study 1 in De Winter and Wagemans 2004, and as Appendix 1 in Wagemans et al 1998). We have tested large samples of subjects with these stimuli and we report the identification rates obtained from them. In addition, we describe reasons for the variations in identifiability and two smaller follow-up experiments testing some of these.

The major reason why we believe these normative data about identifiability of silhouettes and outlines are interesting is that silhouettes have been used in a growing number of studies, which could profit from using larger stimulus sets with known identifiability rates. For example, in a psychophysical study to measure the efficiency of detecting and recognising 3-D objects in luminance noise (Tjan et al 1995), four simple 3-D objects were used (wedge, cone, cylinder, and pyramid), and in a study to test the effect of depth rotation on object identification (Newell and Findlay 1997), six everyday objects were used (bottle, lamp, wineglass, water jug, chair, frying pan). A comparison between different stimulus formats in these and related studies (Hayward 1998; Hayward et al 1999) usually revealed relatively small differences. For example, the efficiencies of recognising 3-D objects were generally quite low in the study by Tjan et al, ranging from $2.69 \%$ for line drawings to $3.28 \%$ for shaded versions and $4.51 \%$ for silhouettes. Likewise, Newell and Findlay found no benefit for the identification of shaded versions over silhouettes when the objects were shown in conventional views, only when they were shown in unconventional views. This kind of results has been taken as a support for the role of outline shape in object recognition (Dell'Acqua et al 2001; Hayward 1998). Although the viewpoint generalisation cost (ie the performance decrement when recognising non-studied views) was not found to be greater for silhouettes than for shaded versions in earlier studies (Hayward et al 1999), a more recent study with simpler shapes consisting of fewer components (Hayward et al 2005) revealed larger silhouette effects. This illustrates the need to test a large variety of objects before drawing firm conclusions.

In a study on 64 objects from the Snodgrass and Vanderwart set, presented as line drawings and as silhouettes, Lloyd-Jones and Luckhurst (2002) found that response times were longer for non-living than for living things and that this category difference was greater for silhouette versions than for the standard line drawings. However, these differences between object categories and stimulus formats were not very pronounced for naming responses, only for responses in an object decision task (ie discriminating between existing objects and structurally related non-objects). This kind of research is important in understanding possible reasons for category-selective object-recognition deficits (for a review, see Humphreys and Forde 2001). These and other object-recognition deficits have frequently been tested with silhouettes (Dehaan and Campbell 1991; Thomas and Forde 2006), but usually with a small set of objects that were highly identifiable for normal, control participants. We present a stimulus set with a large range of identifiability levels in this paper.

(1) A similar process has recently been described for silhouetted face profiles (Davidenko 2007), along with a description and illustration of the theoretical and methodological advantages of silhouettes for face perception. 


\section{Experiment 1: Silhouettes and outlines}

\subsection{Methods}

2.1.1 Participants. 356 first-year students from the Department of Psychology at the University of Leuven participated as part of a course requirement. First-year psychology students in Leuven can be safely assumed to be unfamiliar with the particular line drawings from which our stimuli were derived.

2.1.2 Apparatus. All stimuli were stored in digital form (as PCX files) on the hard disk of an IBM-compatible PC with an Intel Pentium processor, to be retrieved and presented automatically by a $\mathrm{C}^{++}$program used for the on-line control of the experiment. Stimuli were presented in black on a large white screen, attached to the front wall of a large auditorium, through a BARCO Vision or a Data Display system, both operating at a $640 \times 480$ pixel resolution. The screen measured $240 \mathrm{~cm} \times 300 \mathrm{~cm}$ and was viewed from a distance ranging from 4 to $16 \mathrm{~m}$, depending on where in the auditorium the observers were seated. The majority of the participants were seated in the middle rows from which the screen could best be viewed. The auditorium was dimly lit as a compromise to get the best possible contrast in the image while at the same time enabling participants to write down their answers on the response sheet.

2.1.3 Stimuli. Stimuli were modified versions of a standardised set of 260 line drawings of everyday objects, the so-called Snodgrass and Vanderwart (1980) pictures (see figure 1 for examples). (We refer to their Appendix A for the numbered pictures and to their Appendix B for the most frequent names of the objects.) Photocopies of the original drawings as published in the journal article were scanned into the computer and slightly improved with a standard graphics software package (Paint, part of Windows 3.1). We removed noise spots in the background and we removed or added a few pixels here and there to enhance the contours of the line drawings. Silhouette versions of each line drawing were obtained by blackening the complete area enclosed by the picture outline, effectively removing all interior features. This is relatively easy to do because
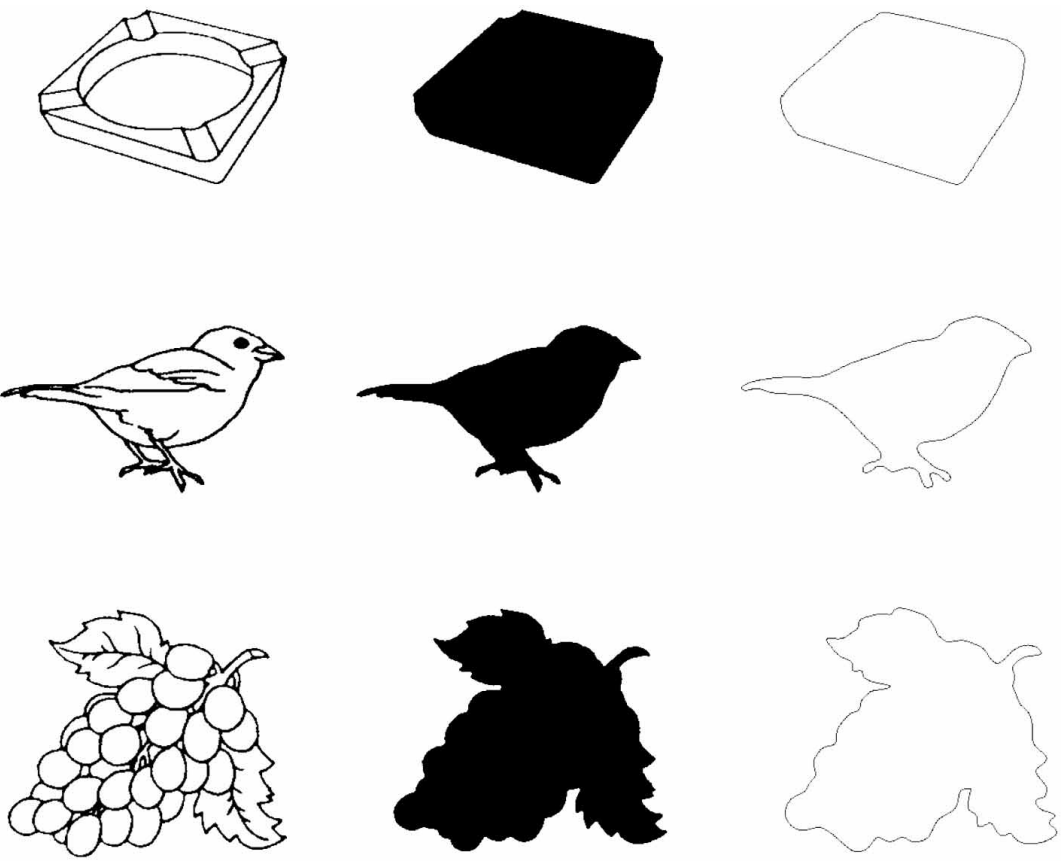

Figure 1. Examples of the stimuli in the three stimulus formats: column 1, line drawings (from Snodgrass and Vanderwart 1980); column 2, silhouette versions; and column 3, outline versions. 
Paint has an option to fill with selected colour an area bordered by a closed line. The major requirement was that the outlines had to be closed (which is why we sometimes had to improve the contours). In most cases, a line drawing could be modified into a silhouette only by filling several smaller areas. This happened when a subregion of the whole shape also had borders that were closed (eg no 109, 'grapes'; no 181, 'pumpkin'; no 233 , 'tiger').

We also filled those parts of the background that were enclosed by the external contour of an object. This happened when an object contained concave parts or empty areas (eg the wheels of no 13, 'baby carriage'; or no 27, 'bicycle'; the holes in no 41, 'button'; or no 52, 'chain'). It also occurred when a part of an object partially occluded another one (which happened frequently with the legs of several animals; eg nos 28, $43,49,73,108$, etc). Because we realised that this procedure would make many objects more difficult to recognise than they would otherwise have been, we modified some of the line drawings, especially of the animals (eg by placing the legs a little bit further apart). Other changes to the original line drawings were applied when an object part had only minimal area (eg the string attached to the 'balloon', no 15; the thread in the 'spinning wheel', no 213; or the 'spool of thread', no 214) or had a detached part (eg the slice of the 'bread', no 36; the airflow around the 'top', no 238). In these cases, we deleted the small part because we were mainly interested in the identifiability of an object as a single closed area.

Outlines were created by extracting the external contours from the silhouettes (after the modifications to the original line drawings). For this, we made use of software developed at the Department of Electrical Engineering at our university (ESAT-PSI-VISICS), building on standard computer-vision algorithms for edge detection and spline-fitting. Contour extraction was done with an implementation of Canny's (1986) algorithm, which returns a chain of boundary points at subpixel accuracy. Through this chain of points, a cubic B-spline curve was fitted with the aid of Dierickx's (1982) software, which is available in the Netlib package (see http://netlib2.cs.utk.edu/dierickx/). This allowed us to calculate curvature information in each individual pixel point of the contour. These procedures produced closed and smoothly curved contours, which were then made discrete again to be presented on standard CRT screens (as PCX files).

The size of the modified pictures was normalised as in the original Snodgrass and Valderwart pictures. On the screen in the auditorium, they subtended about $120 \mathrm{~cm}$ $\times 180 \mathrm{~cm}$, which gives a visual angle between $17 \mathrm{deg} \times 24 \mathrm{deg}$ for the front rows and $4.3 \mathrm{deg} \times 6.4 \mathrm{deg}$ for the back rows.

2.1.4 Design and procedure. Participants were tested in groups of about 90; in this way, they could be seated comfortably in the auditorium with one seat in-between them. Silhouettes and outlines were shown to different groups of subjects. To ensure that they would continue to do their best until the end of the stimulus series, the complete set of pictures was divided into two subsets of 130 pictures, drawn randomly from the original set (which was ordered alphabetically by using the most frequent name). Thus, we organised four sessions, two for the silhouettes (with 85 and 88 subjects) and two for the outlines (with 94 and 89 subjects). The subsets were the same for silhouettes and outlines, and we also used the same random presentation order for both versions, to prevent any differences between them from possibly being an accidental result of the particular stimulus sequence. A session lasted about $35 \mathrm{~min}$, instructions included.

We explained to the subjects that they would be shown silhouettes (or outlines) of everyday objects created by modifying original line drawings. We also explained that this procedure would make some of the pictures virtually impossible to recognise but that we insisted that they tried as well as they could. The subjects were asked to give the most common name that best described the object that was presented in the 
picture; they were explicitly told to avoid overly general words (such as 'thing' or 'animal'), words that were intended to be funny (such as 'inkblot' or 'Big Mac Menu'), and very lengthy descriptions. Instead, they were allowed to indicate on their response sheet that they failed to recognise a picture by putting a small horizontal line segment next to the stimulus number of that picture.

Stimuli were presented for $5 \mathrm{~s}$. The screen then turned black for $3 \mathrm{~s}$, except for a small text bar in the middle of the screen indicating the number of the preceding stimulus ("The preceding stimulus was number $x$ "). A $500 \mathrm{~ms}$ tone of $800 \mathrm{~Hz}$ warned the participants that the next stimulus would be shown after another $2 \mathrm{~s}$, with a black screen and a small text bar indicating the number of the following stimulus ("The following stimulus is number $x+1$ "). A strict timing was imposed to keep subjects motivated while at the same time giving them just enough time to perform the task. Participants did not have to wait until the stimulus disappeared from the screen before writing down the name of the object represented in the silhouette or outline (they could start writing as soon as they had recognised the object). The messages with the stimulus numbers were provided to assist the subjects in keeping track of the stimulus order (to avoid confusions on the response sheet). Responses had to be written down on A4 pages divided vertically into two halves; each half contained two columns, a narrow one with the stimulus number clearly indicated and a wide empty one to be used for writing down the object name. Three pages were needed for the 130 stimuli in a session; they were stapled together in the upper-left corner. When the page had to be turned, subjects could clearly hear the sound of the pages rustling. This also assisted them in keeping track of the correct order. Despite these precautions, two subjects (from the silhouettes condition) failed to write the names of the objects in the appropriate slots indicated on the response sheets. We decided to discard their responses from the analyses instead of trying to figure out where in the sequence they had lost track.

2.1.5 Scoring. We used two kinds of criteria to score the responses as correct or incorrect. In the first, most stringent one, responses were counted as correct only when the same name was given as that listed by Snodgrass and Vanderwart (1980). In the second, more liberal one, synonyms and colloquial names that clearly indicated the same concept were also treated as correct. This was done because we used Flemish subjects in all experiments and Flemish has many more synonyms and colloquial names than English or Dutch (Severens et al 2005). However, remotely related names were not allowed when they referred to clearly distinguishable concepts.

Because borderline cases exist, we developed clear scoring guidelines, which we used throughout this study. These guidelines consisted of the following four rules and a number of extra qualifications and examples. First, a response was considered correct when it referred to the same basic-level category name (eg exact name, synonym, colloquial name, diminutive, incorrect spelling, combined response alternatives including correct basic-level category name). In other words, we were assessing basic-level or entry-level object identification (Jolicoeur et al 1984; Rosch et al 1976). Second, a response was also considered correct when it referred to a more specific exemplar of the basic-level category (ie subordinate level), but only when the exemplar was a prototypical one. For example, 'blackbird' and 'sparrow' were considered correct for 'bird' (no 28) but 'penguin' was not. Third, and complementary, a more general (ie superordinate level) concept was allowed but only when the intended basic-level concept could be considered a typical subset of the more general class. For example, 'fly' (no 93) could be called 'insect' but 'penguin' (no 169) could not be called 'bird'. Of course, the superordinate concept could not be too general. For example, 'bird of prey' was allowed for 'eagle' (no 82) but 'bird' was not. Moreover, it had to be clear that the class level was intended and not the exemplar level. For example, for 'leopard' 
(no 136), 'catlike' and 'feline' were considered correct but 'cat' as such was not (because 'cat' also belonged to the set as an individual object, ie no 49). A consequence of this type of rule is that some concept names were considered correct for two or more basic-level categories contained in the stimulus set (eg multiple insects). Fourth, when a related concept at the same category level was given, it was not considered correct when it had a clearly different shape or when the alternative was also included in the set. For example, 'chicken' (no 55) could not be called 'rooster' (no 191) and 'fly' (no 93) could not be called 'beetle' (no 24) but 'goat' (no 107) could be called 'male goat' or 'billy goat' and 'cow' (no 68) could be called 'bull', 'bullock', or 'ox'. In the same spirit, further specifications were allowed as long as they did not give rise to an alternative that was clearly a different object. For example, 'long skirt', 'full skirt', and 'petticoat' were allowed for 'skirt' (no 205), but 'robe' and 'dress' were not; 'little wagon', 'toy car', and 'go cart' were allowed for 'wagon' (no 249) but 'wheelbarrow' and 'truck' were not.

In the case of uncertainty in the application of these rules, the researchers tried to reach a consensus decision within the spirit of the whole set of names of objects, avoiding inconsistencies as much as possible. When decided, the scoring was written down and similar data sets were scored with the same criteria, guidelines, and reference data. ${ }^{(2)}$ We can make our scoring system available to other researchers who are interested in applying it.

\subsection{Results}

The results are summarised in table 1 (tables follow references). In this table, the first column contains the identification number of each stimulus in the original Snodgrass and Vanderwart (1980) set and the second column includes the correct names in English (ie the official Snodgrass and Vanderwart names). The next five columns contain the data for the silhouette versions and the final five columns those for the outline versions. From left to right, these five columns contain (i) the number of subjects tested with these stimuli, (ii) the number of subjects who gave the exact name, (iii) the number of other alternatives that were considered correct, (iv) the number of blank responses, and (v) the number of other alternatives that were considered incorrect. The cells in the third and fifth of these columns contain multiple numbers of subjects that gave a particular correct or incorrect alternative (from most frequent to least frequent). For example, the cell ' 4,2 , 2, 3(1)' for 'other incorrect' responses for object no 1 ('accordion') in the 'silhouettes' condition refers to four subjects who answered "photo camera (fototoestel)", two who said "photographic equipment (fotoapparaat)", two who said "sofa (zetel)", and then three singular responses, namely "bed (bed)", "camera (camera)", and "suitcase (koffer)".

(2) Five remarks should be added here. First, for the majority of stimuli, the guidelines summarised here were clearly sufficient to yield unequivocal scores. For those stimuli for which some doubt remained, the scoring would not have shifted the degree of identifiability from low to high, or vice versa, but rather within the same level of average identifiability. Second, when the absolute level of identifiability as such is not the major concern, the constancy of these scoring guidelines is most important when one wants to compare levels of identifiability between different versions of the same stimulus set (as we do here to some extent). Third, as mentioned in section 1, we have developed still other versions derived from the same basic set, for instance straight-line versions (De Winter and Wagemans 2008b) and fragmented versions (Panis et al 2008a; Panis and Wagemans 2008; Wagemans et al 1998). In those studies, we have selected subsets of stimuli that were highly identifiable in accordance with the current norms and this selection would not be affected by the uncertainty at the low end of the range. Fourth, in these subsequent studies, the scoring rules were sometimes a bit more liberal than here because some distracting alternatives would no longer be present (eg 'chicken' could then be called 'rooster'). Fifth, in subsequent studies, we started from a digital file with names that were considered correct according to the present data set, so that scoring could be done quasi-automatically. Only the remaining cases of doubt were then scored manually and added to the database. In this way, the data set expanded from one study to the next and the scoring became gradually easier. The present study was actually the first of the whole series. 
This way of summarising the data allows an analysis of strictly correct names (columns 4 and 9) versus correct concepts (columns 4 and 5, and 9 and 10), either as absolute numbers or as proportions (when dividing by columns 3 and 8 , respectively) or percentages (multiplying the proportions by 100). It also allows measures of name agreement, both for correct ones (columns 5 and 10) and incorrect ones (columns 7 and 12). For example, no less than 19 and 17 different (incorrect) alternatives were given for the 'ashtray' (no 10) by the subjects having seen the silhouette or outline versions of it, respectively. The 19 alternatives were given by 19, 9, 4, 2, and 15 single subjects in the silhouette condition, and a similar distribution was obtained for the 17 alternatives in the outline condition $(27,12,3,2,2$, and $12 \times 1)$. Moreover, it indicates when the object is not identified as anything else (large number of blank responses, few alternative incorrect responses) and it gives an impression of clear confusions (eg certain frequently given incorrect responses). For example, 'pepper' (no 170) gave rise to 70 or more blank responses, while 39 and 44 subjects (having seen silhouette and outline versions, respectively) answered "pullover" for 'blouse' (no 29), which was considered incorrect because 'pullover' also belongs to the stimulus set (no 224).

The names given by all the subjects in all of the conditions (the real raw data) are stored in files, along with our judgment of the names being correct $(+)$ or incorrect $(-)$, which we make available on our website (http://ppw.kuleuven.be/labexppsy/johanw/ wag_2D.htm). Because the names themselves are in Dutch (and include Flemish colloquial names and diminutives, etc), they are of limited use for the majority of researchers, except perhaps for researchers in psycholinguistics. The aggregated, scored data are what counts in the context of perceptual research. To be able to focus on the identifiability of the silhouette and outline versions and to assist a comparison across the different experiments from this study, we present the percent exact name and the percent correct concept measures in a separate overview in table 2.

\subsection{Discussion}

2.3.1 Distribution of identifiabil ity. The effect of modifying the line drawings into silhouette versions or outlines was quite different for different objects. For many objects, this manipulation had virtually no effect on identifiability, while for others it made the object virtually unidentifiable. Using the concept criterion and taking the average identifiability for silhouettes and outlines, 112 objects yielded above $90 \%$ correct identification and 56 objects below $10 \%$. Interestingly enough, a whole range of intermediate levels of identifiability (between $10 \%$ and $90 \%$ correct) emerged in the remaining 92 silhouettes and outlines, which makes them quite useful for studies in which ambiguity is desired. For example, it may be quite interesting to have variable levels of identifiability that can then be influenced by priming or context effects. We will return to this possibility in section 5 below.

Moreover, objects also differed in their name agreement (ie how well they agreed in giving the same correct name), more or less independently of their identifiability. Among the objects that were identified quite well at the concept level, the majority had good name agreement but there was also a significant minority that gave rise to multiple names or alternative names that were given frequently. Among the objects that were identified quite poorly, the majority gave rise to a large number of blank responses as well as to a large variety of other objects that apparently could be seen in the silhouette or outline version. However, a significant minority gave rise to a single incorrect alternative. These types of naming errors may also be applied usefully in other studies. For some purposes, it may be interesting to have pictures of objects (silhouettes or outlines) that look like objects but that do not give rise to the impression of anything else (large number of blank responses, few incorrect alternatives), or that give rise to the impression of many things (large number of incorrect alternatives), 
or that remind one of a single other object (very frequent, small number of alternative names indicating the same incorrect concept). It is because of this potential usefulness for other research purposes that we make this data set of identification norms of silhouettes and outlines available to other researchers (see also section 5).

Our stimulus set could be divided roughly in five categories, based on the performance at concept level identification in the outline versions and on the agreement in correct or incorrect naming. The first is a large category of objects $(n=93)$ with excellent identifiability $(\geqslant 85 \%)$ and good name agreement $(\geqslant 75 \%)$. The number of biological objects $(n=51)$ in this category is quite striking. A second category $(n=35)$ consists of objects that are well-identified but that are given multiple names. The third is a large category $(n=64)$ of objects of average identifiability and averageto-good name agreement. Fourth is a small category $(n=16)$ of objects that are not identified correctly but that are named incorrectly rather consistently. Examples of these are no 58 ('cigar' $\rightarrow$ 'pencil'), no 206 (skunk' $\rightarrow$ 'squirrel'), no 222 ('sun' $\rightarrow$ 'ball'), and no 260 ('zebra' $\rightarrow$ 'horse'). The fifth and final category is a large category again $(n=52)$ of objects that are virtually unidentifiable and that give rise to a large number of blank responses or a variety of incorrect names. In the following section, we discuss why some objects cannot be identified as silhouettes or outlines.

2.3.2 Reasons for unidentifiability. 51 stimuli from the original set of 260 line drawings were virtually unidentifiable as silhouettes or outlines (ie $\leqslant 10 \%$ correct concept, in both versions). A number of reasons may have caused this loss of information from the original line drawing to the silhouette or outline version (see figure 2).

First, in some cases (see figure 2a), some crucial internal features (eg texture, surface markings) have disappeared or we had removed some disjoint but highly diagnostic features (eg the smoke of the cigar, the rays of the sun). As a result, the following ten objects could not be identified (we mention their number in the original set): 'cigar' (no 58), 'clock' (no 60), 'eye' (no 86), 'hair' (no 113), 'lettuce' (no 137), 'nail file' (no 152), 'ruler' (no 192), 'sun' (no 222), 'watermelon' (no 252), and 'zebra' (no 260).

Second, as mentioned in the stimulus section above, we have also filled the holes belonging to the object or some parts of the background that were enclosed by parts of the object (see figure 2b). As a result, the following eight objects could no longer be identified: 'button' (no 41), 'ladder' (no 131), 'pocket book' (no 178), 'ring' (no 187), 'spinning wheel' (no 213), 'swing' (no 225), 'well' (no 253), and 'wheel' (no 254).

Third, in many cases, the 3-D surface discontinuities that are normally captured by internal lines appeared to be crucial for object identification. This was the case for polyhedral objects as well as smooth objects. Seven polyhedral objects were not identified (see figure 2c): 'accordion' (no 1), 'barn' (no 17), ‘box' (no 35), 'light switch' (no 139), 'record player' (no 184), 'refrigerator' (no 185), and 'stove' (no 219). Ten smooth objects suffered dramatically too (see figure 2d): 'artichoke' (no 9), 'asparagus' (no 11), 'cloud'; (no 62), 'corn' (no 66), 'ear' (no 83), 'nose' (no 155), 'peach' (no 163), 'pepper' (no 170), 'pumpkin' (no 181), and 'toe' (no 235). There were also eight unidentified objects that consisted of both polyhedral and smooth parts (see figure 2e): 'ashtray' (no 10), 'cake'; (no 42), 'cap' (no 46), 'drum' (no 80), 'envelope' (no 85), 'nut' (no 156), 'sandwich' (no 195), and 'train' (no 240). Finally, there were also eight objects (see figure 2f) that could not be identified for a number of combined reasons (surface structure lost and hole filled or internal features gone): 'basket' (no 20), 'belt' (no 26), 'clown' (no 63), 'door' (no 76), 'necklace' (no 153), 'sled' (no 207), 'top' (no 238), and 'window' (no 257).

2.3.3 Differences between living and non-living objects. As mentioned in section 1, there is an extensive literature on category-selective object-identification deficits (see Humphreys and Forde 2001). More specifically, some brain-damaged persons show selective difficulties in the identification of living things. Although it is tempting to attribute this 
category-selective impairment to some fundamental difference between semantic categories (eg with sensory properties being more important for living things and functional properties for non-living things), it has also been proposed that it may be a rather artifactual consequence of a normal processing difference between structurally similar object categories such as fruits, vegetables, and animals, and structurally distinct object
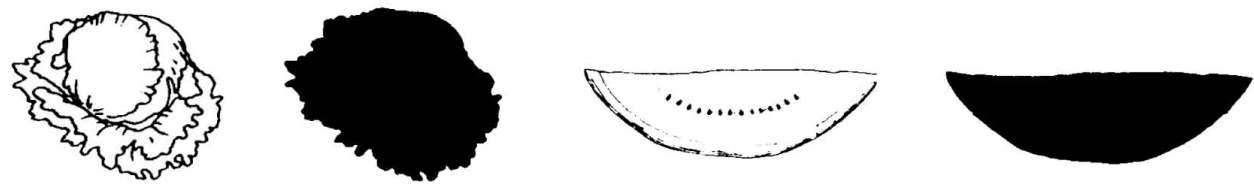

(a)

b)
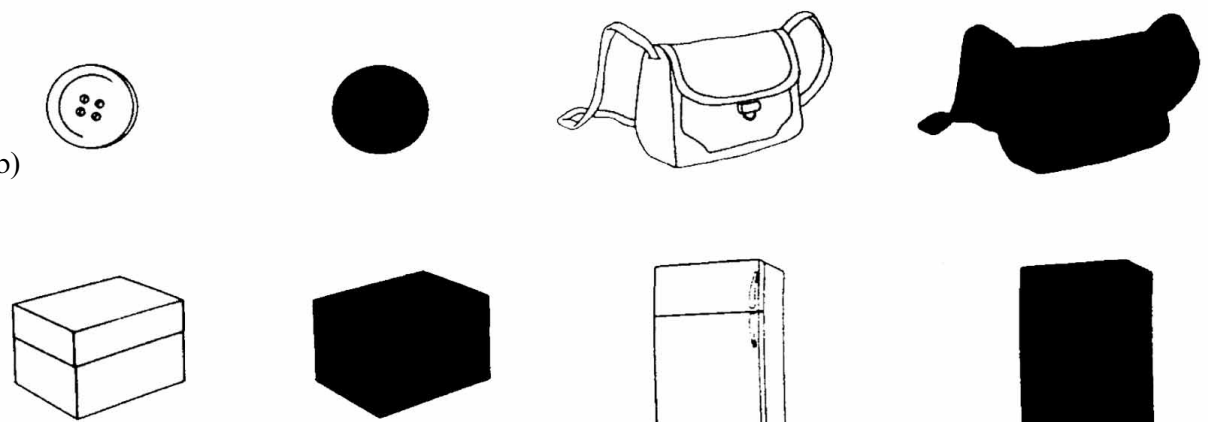

(c)
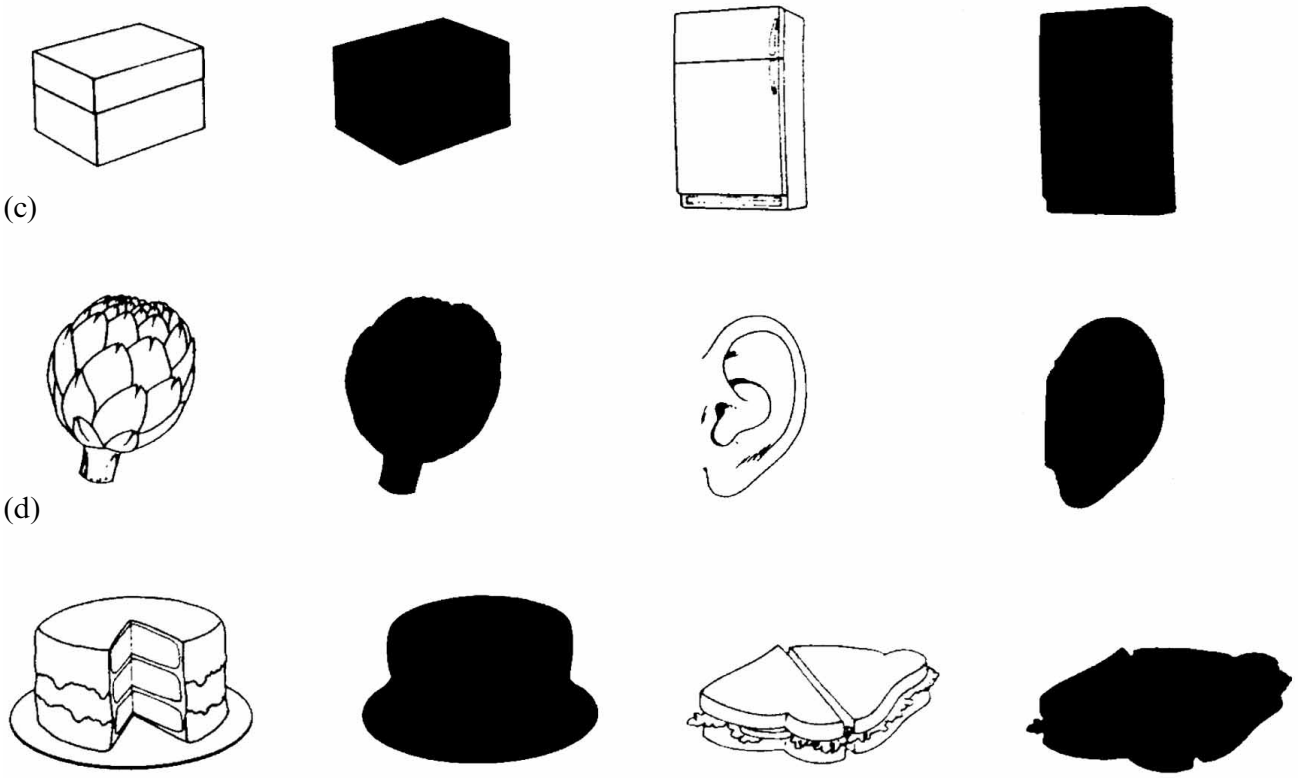

(e)
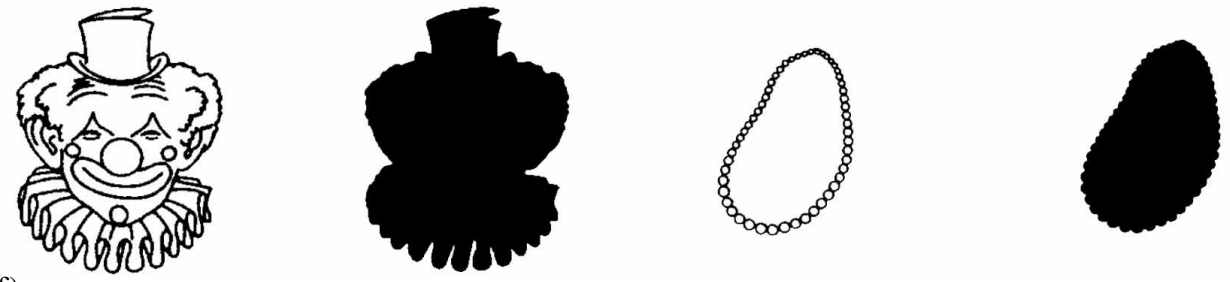

(f)

Figure 2. Examples illustrating different reasons for unidentifiability of the silhouette versions: (a) crucial internal features are missing, (b) holes or parts of the background are filled-in, (c), (d), and (e) internal lines representing the 3-D surface discontinuities are missing (for polyhedral objects, smooth objects, and objects consisting of polyhedral and smooth parts, respectively), and (f) mixture of reasons. 
categories such as clothing, furniture, and vehicles (Humphreys et al 1988; Lloyd-Jones and Humphreys 1997). On the basis of a careful analysis of this complicated literature, Lloyd-Jones and Luckhurst (2002) predicted a processing difficulty for non-living relative to living things in conditions where processing would be mediated primarily by information about the outline contour. They tested and confirmed this prediction by using silhouette versions of 64 stimuli from the Snodgrass and Vanderwart (1980) set in an object decision and naming task: the response times were longer for the subset of 32 non-living objects than for the 32 matched living objects (for a list, see their Appendix A), especially for the silhouette versions and the object decision task. Although our silhouette versions were not necessarily identical to theirs (eg because we filled-in the background regions that were enclosed by the external contour), we could verify the identifiability in the same subgroups of objects $(2 \times 32)$ in our data sets. In all four data sets (silhouettes as well as outlines and correct name as well as correct concept), the identifiability of the living objects was higher than that of the non-living objects. For example, taking the correct-concept criterion, the silhouette versions of the living objects were identified correctly in $82.01 \%$ of the cases and the non-living ones in only $59.48 \%$, averaged across the relevant stimuli $\left(t_{62}=2.51\right.$, $p=0.0147$ ), and for the outlines the corresponding difference was $79.39 \%$ against $57.89 \%$, respectively $\left(t_{62}=2.38, p=0.0206\right)$. This finding confirms the earlier results of Lloyd-Jones and Luckhurst, although their differences were numerically smaller and not always statistically significant in the naming task (probably because of the mentioned stimulus differences and because our sample size was much larger).

2.3.4 Differences between silhouettes and outlines. In table 2 one can see that the average identifiability across the whole set of 260 objects is somewhat higher for the silhouette versions than for the outline versions, both when taking the exact names $(53.21 \%$ versus $51.79 \%)$ and when using the more liberal correct-concept criterion $(64.70 \%$ versus $61.85 \%$ ). Because we believe the correct-concept criterion is a more valid measure of basic-level category identification, we will focus on this criterion in the remainder of this paper. Although the difference in identifiability is numerically small $(2.85 \%)$, it is statistically significant across all pairs of stimuli $\left(t_{259}=4.44, p<0.001\right)$. For 129 pairs, silhouettes are identified better than outlines; for 52 there is no difference (either because both are identified perfectly, in 36 cases, or because both are not identified at all, in 16 cases); and for 79 pairs silhouettes are identified worse than outlines. To try to understand this difference, we examined the objects that yielded a strong silhouette advantage and we noticed that their normal surface colour was relatively dark (eg no 18 'barrel', no 205 'skirt', no 221 'suitcase', no 189 'roller skate', no 38 'broom', no 95 'football', no 183 'racoon', etc). At the other extreme, it was very striking to see that no 124 'ironing board' was much easier to identify in the outline version $(74 \%$ difference in the opposite direction). Perhaps in this case the thin lines of the supporting part can be seen as the iron tubes themselves and the white surface in-between as the open air (or background) between them; in the silhouette version, this part is completely black and that appears to be very misleading. Also the iron itself (no 123), which is usually white nowadays, shows a rather exceptional outline advantage (28.67\%); the glass (no 104), a typically translucent object, yields a $24.40 \%$ identifiability advantage for the outline version. In other words, perhaps this difference between silhouette versions and outline versions has something to do with the 'black' and 'white' corresponding more or less to the natural surface colour of the object that is depicted.

To explore this hypothesis further, we asked four observers to rate the darkness of the standard surface of the objects in the Snodgrass and Vanderwart set on a sevenpoint scale, from 1 for certainly white or translucent to 7 for certainly black or very dark. Observers had to perform this rating task based on their visual memory or visual 
imagery because only the names were given, not the images themselves, to avoid any bias from the image as such. We correlated the average darkness rating with the silhouette advantage and obtained a small but positive correlation of 0.1285 , which is just statistically significant $(p=0.037)$, owing to the large number of observations $(\mathrm{df}=257)$. This seems to suggest that subjects in the identification task may have relied, unintentionally perhaps, on their (implicit or explicit) knowledge of the average or normal surface colour of the objects depicted in the silhouettes and outlines, and that this has produced a small but significant advantage for the silhouettes because, apparently, there were somewhat more typically 'dark' objects than typically 'light' ones in the Snodgrass and Vanderwart set (129 objects with a darkness rating $>4$ versus 100 with one $<4$ ). Note, however, that the correlation may also be spurious: Removing the three data points with the lowest difference score (ie only $1.15 \%$ of the stimuli) reduces the correlation to $0.077(p>0.10)$. Before drawing any firm conclusions about the silhouette advantage and the possible reason behind it, an extra experiment seems to be required.

2.3.5 Additional experiments. We wanted to test two possible hypotheses why silhouettes may have been easier to identify than outlines in experiment 1 , by using inverted-contrast silhouettes (white objects on a black background) in experiment 2. The first reason was proposed before: perhaps there is a small silhouette advantage because they profit more from a correspondence with the natural surface darkness of a number of objects in the stimulus set. The small positive correlation with darkness ratings could be taken as suggestive evidence for this hypothesis. With inverted-contrast silhouettes the advantage should disappear (compared to the outlines) or switch into a disadvantage (compared to the original, black silhouettes). A second reason for the poorer identifiability of the outlines may be that the thin outlines do not define the contour of the shape as clearly as a silhouette. If that was the case, inverted-contrast silhouettes should be more identifiable than outlines. If the correlation with darkness ratings was not spurious, it should become negative for inverted-contrast silhouettes.

We also wanted to examine what the effect was of filling the holes of certain objects and blackening certain parts of the background when surrounded by object parts in experiment 1 , by not doing that in new silhouette versions in experiment 3 .

\section{Experiment 2: Inverted silhouettes}

\subsection{Methods}

3.1.1 Participants. 234 first-year students from the Department of Educational Sciences at the University of Leuven participated as part of a course requirement. These students can be safely assumed to be unfamiliar with the particular line drawings from which our stimuli were derived.

3.1.2 Apparatus, stimuli, design, and procedure. Testing took place in the same auditorium with the same equipment and viewing conditions. Stimuli were inverted-contrast silhouette versions of 235 line drawings of everyday objects, drawn from the Snodgrass and Vanderwart (1980) set. We started from the silhouette versions used in experiment 1 but we inverted the contrast polarity: instead of using black silhouettes on a white background, we now used white silhouettes on a black background. 25 stimuli that were identified perfectly $(n=9)$ in all of the four data sets from the previous experiment (correct name and correct concept, in silhouette and outlines version) or not at all $(n=16)$ in any of them, were excluded from the present stimulus set to shorten the test sessions to about $30 \mathrm{~min}$, instructions included. The remaining stimuli were divided randomly into two subsets ( $n=118$ and $n=117)$ to be assigned to two subgroups of participants (odd and even student numbers from the same year, $n=116$ and $n=118$, respectively). Instructions and testing procedures were the same as in experiment 1. 


\subsection{Results and discussion}

The aggregated identifiability rates (exact names as well as correct concept) are included as columns 7 and 8, respectively, in table 2. It is clear from these results that the average identifiability (eg correct concept) is higher for the inverted-contrast silhouettes in experiment $2(76.51 \%)$ than those for the silhouette and outline versions of the same stimuli in experiment $1\left(67.76 \%\right.$ and $64.60 \%$, respectively) $\left(t_{234}=6.35\right.$ and 8.52 , $p<0.001$ ). The correlation of the inverted-contrast silhouette (white-on-black) advantage with the darkness ratings is now $-0.0544(p=0.21)$ compared to the standard (black-on-white) silhouettes and $0.0136(p=0.42)$ compared to the contours. Hence, despite the large number of observations $(\mathrm{df}=232)$, the correlations are now no longer statistically significant.

The conclusion from this control experiment is straightforward. Both kinds of silhouette versions are somewhat easier to identify than the outlines, probably because they have contours that are somewhat better defined. The contours are defined by a larger contrast (dark and white regions with an extended surface area rather than a thin line) and the spline-fitting which is used for the outlines may have smoothed the edges and vertices too strongly in some cases so that they become more curved in the outline versions than in the silhouette versions (compare carefully the examples in columns 2 and 3 in figure 1). It is clear that knowledge of surface darkness or lightness has not played a role in the identification differences between the different versions. Why inverted-contrast silhouettes yielded the highest identification rates is unclear because a number of factors may have contributed to this advantage: (i) a perceptual effect (eg white figures may be more salient than black ones and their contours are better defined than in outline versions), (ii) a set effect (eg less cross-talk amongst the remaining stimuli within the subset), (iii) a motivation effect (eg because the experiment comprised fewer stimuli and the most difficult ones were removed from the set), (iv) a classroom effect (eg shorter distances between participants in the larger groups), (v) a sample effect (eg more highly idiosyncratic responses amongst psychology students than amongst students from educational sciences), etc.

\section{Experiment 3: New silhouettes}

\subsection{Methods}

4.1.1 Participants. 83 fourth- and fifth-year students from the Department of Architecture at the University of Leuven participated as part of a course requirement. These students can be safely assumed to be unfamiliar with the particular line drawings from which our stimuli were derived.

4.1.2 Apparatus, stimuli, design, and procedure. Testing took place in a similar auditorium with the same equipment and viewing conditions as in experiments 1 and 2. Stimuli were normal (black-on-white) silhouette versions, again of 51 line drawings of everyday objects, drawn from the set of Snodgrass and Vanderwart (1980) pictures. This subset consisted of those pictures that gave rise to filled holes or blackened background pieces in experiment 1 (for a stimulus list, see table 2). In the new silhouette versions, this filling-in of holes or background pieces was no longer done (see figure 3 for some examples). In some stimuli, this difference concerned only a very small part (eg the ring on top of the 'anchor', no 4; the enclosed part at the bottom end of the 'wrench', no 259). In other stimuli, a considerable part of the background was now left white rather than being made black (eg oval background part enclosed by the 'belt', no 26; complete interior of thin wireframe 'hanger', no 116). Instructions and testing procedures were the same as in experiments 1 and 2. 

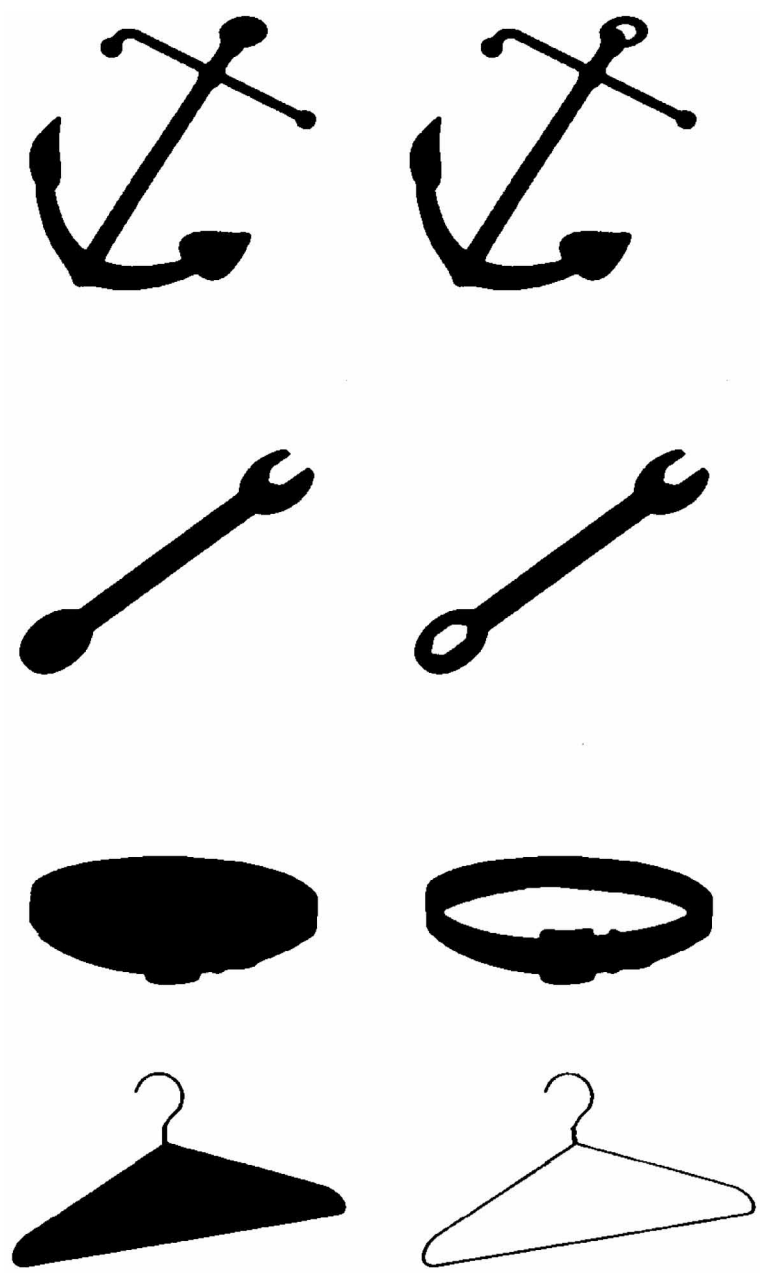

Figure 3. Examples illustrating differences between silhouettes with and without filled-in background parts (used in experiments 1 and 3 , respectively).

\subsection{Results and discussion}

The aggregated identifiability rates (exact names as well as correct concept) are included as columns 9 and 10, respectively, in table 2. It is clear from these results that the average identifiability (eg correct concept) is higher for the new silhouettes in experiment 3 than for the original silhouettes in experiment $1(96.08 \%$ and $60.62 \%$, respectively) $\left(t_{50}=6.10, p<0.001\right)$. The effect of not filling-in the holes or the background parts can be very substantial. For example, in the subset of 12 stimuli where we attributed the unidentifiability to the filling-in of holes or background parts (ie the 8 stimuli from the second group of objects discussed in section 2.3.2 and nos 20, 26, 153 , and 207 , from the final group with mixed reasons), not filling the holes and parts of the background in the new silhouettes made the identifiability (eg correct concept) increase from virtually zero $(0.87 \%)$ to almost perfect $(94.58 \%)$. Somewhat smaller effects occurred for other objects in which the filling-in part was smaller or less diagnostic.

\section{Discussion}

\subsection{Identification norms}

We have tested identification of silhouette and outline versions of the Snodgrass and Vanderwart (1980) set of pictures of everyday objects in large samples of participants $(84,87,89$, and 94 in experiment 1; 116 and 118 in experiment 2; and 83 in experiment 3). 
There was a large subset of these stimuli that remained highly identifiable (112 stimuli $>90 \%$ correct concept) but there was also a significant number that were virtually unidentifiable (56 stimuli $<10 \%$ correct concept). The remaining group showed a big range of identifiability ( 92 stimuli between $10 \%$ and $90 \%$ correct concept). In addition, there was a considerable variation in the kind of errors being made: some stimuli looked like nothing in particular (large number of blank responses, few alternative responses), others looked like one particular other thing (one highly frequent incorrect response), and still others looked like many different things (large number of different incorrect responses).

These data provide good norms for identifiability, which can be used in future research. When one is interested in the identifiability of versions that are derived from these outlines, for instance, by replacing the continuous, curved contour by straightline segments connected at the vertices (ie straight-line versions) or by discontinuous, curved fragments (ie fragmented versions), like we have done in some of our studies (De Winter and Wagemans 2008b; Panis et al 2008a; Panis and Wagemans 2008; Wagemans et al 1998), it is useless to include objects that cannot be identified on the basis of the complete outline. Rather than relying on one's own impression or just asking a few independent judges (Lloyd-Jones and Luckhurst 2002), one can now use objective identification norms. The same is true when one wants to use silhouettes in neuropsychological studies, for instance in the context of category-selective impairments for living or non-living things (Humphreys and Forde 2001; Thomas and Forde 2006), where a larger range of identifiability may be useful for detecting subtler forms of deficit. When one needs a group of well-identifiable objects as well as unidentifiable objects to investigate the effect of top-down influences (eg on segmentation; see De Winter and Wagemans 2006), one can now use subsets from the same set rather than including artificial non-objects. A lot of psychophysical research on 3-D shape that works with silhouettes could now be extended to 3-D objects that differ in the extent to which their 2-D silhouettes are recognisable (Cortese and Andersen 1991; Norman and Raines 2002; Norman and Todd 1994).

In other studies, the group of objects with intermediate levels of identifiability may also be particularly useful. For example, instead of creating ambiguous figures by morphing between two extremes (Gillebert et al 2006; Jiang et al 2007; Panis et al 2005, 2008b; Vangeneugden and Wagemans 2004; Verstijnen and Wagemans 2004), one can now use outlines of objects with multiple possible interpretations because of their own intrinsic ambiguity. Because one can easily disambiguate these stimuli, by filling-in the interior details of the original line drawings, one can study the different stages leading to identification (Bar et al 2001), including the mechanisms for hypothesis testing (Bar 2003; Bar et al 2006) and the possible interference effects resulting from them (Bruner and Potter 1964). One can also investigate the effect of the scene context on identification of ambiguous pictures (eg bread versus mailbox in kitchen scene versus street scene; see Palmer 1975) without having to distort the pictures or flashing them briefly. One can also use different kinds of priming (eg perceptual versus conceptual) to examine when and how an ambiguous image becomes disambiguated (for a review, see Henson 2003).

Experiments in which one switches between stimulus formats for some particular reason could profit from the availability of a larger stimulus set with known levels of identifiability in the different formats. For example, Moore and Engel (2001) have studied whether the object-selective areas in the human brain encode 2-D or 3-D shape by using two-tone images derived from shaded images of complex 3-D objects, shown with or without knowledge about the original 3-D object (ie with or without priming). The same could now be done with a much larger set of stimuli derived from everyday objects (shaded versions by Rossion and Pourtois 2004; line drawings by Snodgrass 
and Vanderwart 1980; silhouettes and outlines from the present study). In a study on reaching and grasping 2-D and 3-D objects, Castiello et al (1998) switched between a 3-D version of an apple and a 2-D silhouette version of it (or vice versa), examining the change from 3-D whole-hand prehension to a 2-D precision grip (or vice versa). It is obvious that a larger set of objects (or images of them, suggesting either 3-D or 2-D interpretations) would be interesting for this kind of research. We have already begun to explore the effect of recognisability on the way in which people grasp plastic shapes derived from our stimulus set to examine how motor constraints on grasping interact with perceptual factors (Wagemans et al 2007). The question whether the same representation is activated when the shape is shown in different formats (eg grey-scale images, line drawings, silhouettes, outlines, etc), known as the issue of cue invariance, has been intensively studied both in humans (Grill-Spector et al 1998; Kourtzi and Kanwisher 2000) and in animals (Brincat and Connor 2004; Sereno et al 2002; Young et al 2001). This research could now also include recognisability as a factor, when making use of the Snodgrass and Vanderwart set, in the original as well as the enriched and impoverished formats.

\subsection{Silhouette-outline difference}

In addition to providing large stimulus sets with reliable identification norms, we also explored a number of issues regarding the variability of identifiability between stimuli and stimulus formats in the present study. In experiment 1, we noticed that silhouettes seemed to be slightly more recognisable than outlines and we speculated that this silhouette advantage was due to a number of objects with natural black or dark surface colours. Despite some initial support from a statistically significant correlation with darkness ratings, this explanation was ruled out in experiment 2 , where inverted silhouettes (white objects on a black background) were generally easier to identify and the correlations were no longer significant. This suggests that silhouettes are somewhat easier to identify than outlines because their contours are defined somewhat better.

One way in which the contour is defined better in silhouettes than in outlines is a technical consequence of the procedures used to create the different versions: the silhouettes preserved the original contours, while in the outlines they were smoothed by the spline-fitting procedure. Note that this spline-fitting procedure was necessary to obtain continuous curvature values along the contour, which we needed for our subsequent work on the role of curvature singularities in object segmentation (De Winter and Wagemans 2006) and object perception (De Winter and Wagemans 2008a, 2008b; Panis et al 2008a). However, it also creates a small but perhaps significant contour difference which may contribute to the observed identification difference between silhouettes and outlines. We have examined the contribution of this small contour difference by computing the pixel difference between the silhouette and outline versions of the whole stimulus set. The procedure to compute the pixel difference consists of three steps: (i) filling-in the outline, (ii) overlaying both shapes (silhouette and filled-in outline), and (iii) counting all the pixels that are different (at both sides of the contour, both inside and outside). Because the absolute number of pixels did not seem very relevant, we have divided the pixel difference by the total number of pixels in the silhouette version (ie the size of the difference relative to the overall size). The average relative difference was quite small $(2.70 \%, \mathrm{SD}=2.34 \%)$. The range was considerable, varying between $0.70 \%$ and $18.25 \%($ median $=1.925 \%$ ), but the majority had small pixel differences (Pc $75=3.24 \%$; only 28 stimuli had a difference of $5 \%$ or more; only 5 had a difference of $10 \%$ or more). More importantly, we have computed the correlation between this relative pixel difference and the identification difference. This correlation was not statistically significant $(-0.102, p=0.099)$ and the tendency actually went in the wrong direction (outline advantage for large pixel differences). 
Figure 4 shows some examples. The 'comb' (no 65) gave rise to a rather substantial pixel difference $(15.53 \%)$ but it was perfectly identifiable in both cases. The 'bee' (no 23) also had a sizeable pixel difference (8.24\%) but identification was rather low in both cases (34.48\% versus $39.33 \%$ for silhouette and outline, respectively). The 'knife' (no 130) showed only a small pixel difference $(2.45 \%)$ but a sizeable identification advantage for the outline $(57.47 \%$ versus $76.40 \%$ ) whereas the 'desk' (no 72 ) showed a sizeable identification advantage for the silhouette $(26.44 \%$ versus $1.12 \%)$ with a small relative pixel difference $(3.01 \%)$. The fact that the difference between the contours is perceptually very salient in this case may indicate that the division by the total area may not have been the ideal choice to normalise the pixel difference. We have, therefore, also normalised the pixel difference by the contour length. A measure of 1 now means that for each pixel along the contour there is a one-pixel difference between the silhouette and the outline. In the case of the 'desk', this measure is 1.70; for the whole set the mean was $0.76(\mathrm{SD}=0.33$, range between 0.47 and 2.59 , median $=0.58$, Pc $75=0.81)$. The correlation between this measure and the identification difference was now statistically significant but negative $(-0.169, p=0.006)$, so going in the wrong direction.
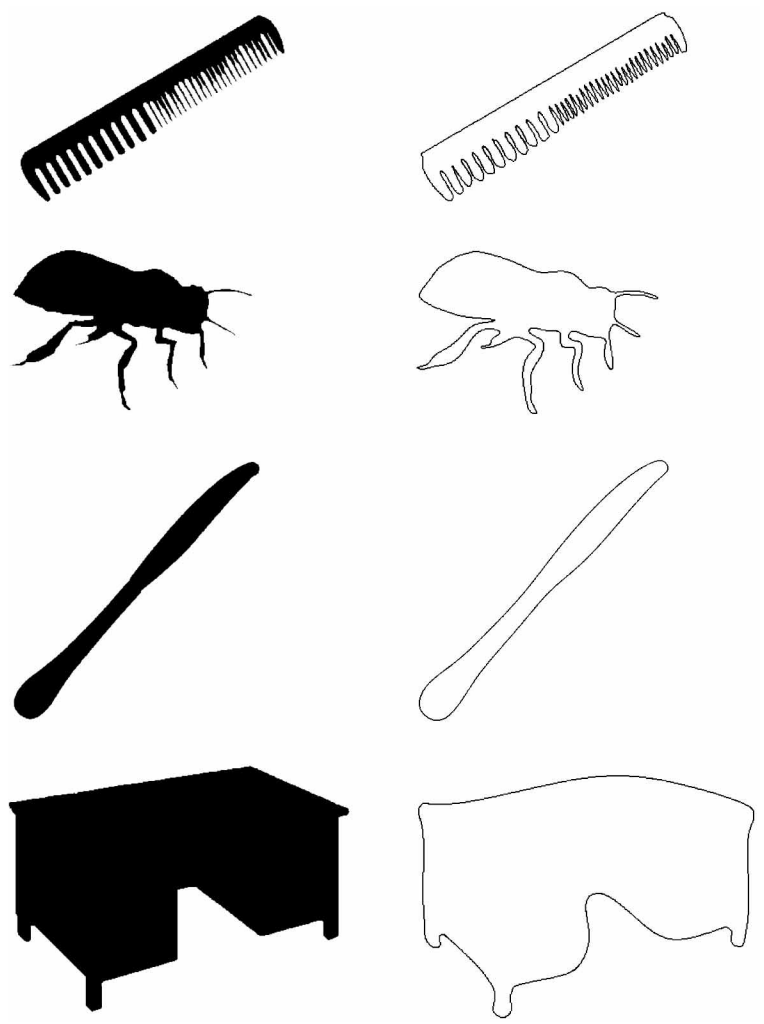

Figure 4. Examples illustrating contour differences between the silhouettes and the outlines.

In sum, the contour difference may have played a role in some cases (eg when the sharp vertices which have become more rounded in the outlines were diagnostic) but the mere pixel difference between the contours was small and it had a negligible effect (which even went in the direction of an outline advantage rather than a silhouette advantage). To test the effect of the quality of the contour difference (ie better visible contour with silhouettes than with outlines), one would have to repeat the experiment with outlines consisting of the 'pure' contour (ie without spline-fitting) or with silhouette versions of the current set of outlines (ie with spline-fitting but then filled-in by black). In comparison with the present set of results, such an additional experiment may constitute an interesting 
first step in the direction of discovering 'diagnostic' contour features (ie critical contour fragments with their exact curvature properties and curvature discontinuities). On the basis of our own impression of the perceptible differences between the silhouette and outline versions, this will not be an easy investigation. For the examples in figure 1, for instance, there are perceptible differences in the shapes of the corners and vertices between the silhouettes (middle column) and the outlines (right column) and one could expect these to be important but this is not supported by the data: the 'ashtray' (no 10) was not identified in both versions $(0 \%$ versus $0 \%$, respectively); the 'bird' (no 28) is identified almost perfectly in both cases $(98.35 \%$ versus $100 \%$, respectively); and the 'grapes' (no 109) are identified somewhat better in the slightly more smoothed outline version (40.48\% versus $47.17 \%$, respectively). The lack of an identification difference when complete shapes are presented for $5 \mathrm{~s}$ and basic-level identification is required does not rule out that small differences at particular shape features do play a role when identification is pressed by presenting only contour fragments for $5 \mathrm{~s}$ (Panis et al 2008) or much shorter time (Panis and Wagemans 2008) or when differentiation between exemplars of a basic-level category is required (Op de Beeck et al 2000; Op de Beeck and Wagemans 2001; Panis et al 2008b; Vangeneugden and Wagemans 2004).

\subsection{Why identification sometimes fails}

In a preliminary analysis of the subset of stimuli that were almost impossible to identify, we distinguished several reasons why silhouette and outline versions are no longer recognisable, ranging from the loss of 3-D structure (very frequent in man-made objects drawn in perspective) to the loss of distinctive surface markings (eg the stripes of the zebra) or the filling-in of holes or parts of the background enclosed by object parts. The role of the latter cause of unidentifiability was verified in experiment 3, where we presented silhouette versions without this filling-in of background elements, so depending on the needs (one single closed contour or good identifiability) one can use one of both versions. More generally, our exploration of the reasons for unidentifiability of silhouette versions derived from line drawings of a large, representative set of everyday objects may be a first step toward a more thorough study of the ecology of line drawings and the information content in 2-D pictures of 3-D objects, as well as the role of surface characteristics (texture, colour) and interior features (L-, T-, and Y-junctions) relative to the role of the outline shape (Biederman and Ju 1988; Hayward 1998; Lloyd-Jones and Luckhurst 2002).

\subsection{Conclusion}

In sum, this study has addressed the recognisability of silhouettes and outlines by testing a large number of stimuli and participants. These data are useful in their own right and as an important step for a large variety of future studies which could profit from these solid identification norms. We have given a number of examples of these possible applications, some of which we have already started to pursue. We encourage other researchers to exploit the potential of these stimulus sets by making them available on our website, along with the present description of the identification data and the complete data base of correct and incorrect names.

Acknowledgments. This research was supported by a research grant from the University of Leuven Research Council (OT/00/007) and from the Research Foundation (FWO Flanders, G.0189.02N) to JW. This study is part of a larger research program with financial support from the University Research Council (GOA/2005/03-TBA) to the Laboratory of Experimental Psychology. We would like to thank Wim Fias for scanning the pictures; Christian Chukwumezie for assistance in modifying the pictures; Toon Sykora for general technical assistance; Inge Meire, Wim Notebaert, and Eva Van de gaer for assistance in data collection; Lien Van Eylen and Betty Vandenbavière for assistance in data management; Tom Putzeys for computing the pixel differences between silhouettes and outlines; and Marco Bertamini and Farley Norman for comments on a previous draft. 


\section{References}

Attneave F, 1954 "Some informational aspects of visual perception" Psychological Review 61183 - 193

Bar M, 2003 "A cortical mechanism for triggering top-down facilitation in visual object recognition" Journal of Cognitive Neuroscience 15 600-609

Bar M, Kassam K S, Ghuman A S, Boshyan J, Schmid A M, Dale A M, Hämäläinen M S, Marinkovic K, Schacter D L, Rosen B R, Halgren E, 2006 "Top-down facilitation of visual recognition" Proceedings of the National Academy of Sciences of the USA $103449-454$

Bar M, Tootell R B H, Schacter D L, Greve D N, Fischl B, Mendola J D, Rosen B R, Dale A M, 2001 "Cortical mechanisms specific to explicit visual object recognition" Neuron $29529-535$

Biederman I, 1987 "Recognition-by-components: A theory of human image understanding" Psychological Review 94115 - 147

Biederman I, Ju G, 1988 "Surface versus edge-based determinants of visual recognition" Cognitive Psychology $2038-64$

Bleumers L, De Graef P, Verfaillie K, Wagemans J, 2007 "Figure-ground segmentation and shape perception as a function of contour alignment and familiarity" paper presented at the 14th European Conference on Eye Movements (ECEM), August, Potsdam, Germany

Braje W L, Tjan B S, Legge G E, 1995 "Human efficiency for recognizing and detecting lowpass filtered objects" Vision Research 352955 - 2966

Brincat S L, Connor C E, 2004 "Underlying principles of visual shape selectivity in posterior inferotemporal cortex" Nature Neuroscience 7880 -886

Bruner J S, Potter M C, 1964 "Interference in visual recognition" Science $144424-425$

Canny J, 1986 "A computational approach to edge detection" IEEE Transactions on Pattern Analysis and Machine Intelligence PAMI-8 679-698

Castiello U, Bonfiglioli C, Bennett K, 1998 "Prehension movements and perceived object depth structure" Perception \& Psychophysics $60662-672$

Cortese J M, Andersen G J, 1991 "Recovery of 3-D shape from deforming contours" Perception \& Psychophysics 49315 - 327

Cycowicz Y M, Friedman D, Snodgrass J G, Rothstein M A, 1997 "Picture naming by young children: Norms for name agreement, familiarity and visual complexity" Journal of Experimental Child Psychology $65171-237$

Davidenko N, 2007 "Silhouetted face profiles: A new methodology for face perception research" Journal of Vision 7(4) 1 - 17 http://journalofvision.org/7/4/6/, doi:10.1167/7.4.6

Dehaan E H F, Campbell R, 1991 "A 15 year follow-up of a case of developmental prosopagnosia" Cortex $27489-509$

Dell'Acqua R, Job R, Grainger J, 2001 “Is global shape sufficient for automatic object identification?" Visual Cognition $8801-821$

De Winter J, Wagemans J, 2004 "Contour-based object identification and segmentation: Stimuli, norms and data, and software tools" Behavior Research Methods, Instruments, and Computers $36604-624$

De Winter J, Wagemans J, 2006 "Segmentation of object outlines into parts: A large-scale integrative study" Cognition 99275 - 325

De Winter J, Wagemans J, 2008a "Perceptual saliency of points along the contour of everyday objects: A large-scale study" Perception \& Psychophysics 70 50-64

De Winter J, Wagemans J, 2008b "The awakening of Attneave's sleeping cat: Identification of everyday objects on the basis of straight-line versions of outlines" Perception $37245-270$

Dierickx P, 1982 "A fast algorithm for smoothing data on a rectangular grid while using spline functions" SIAM Journal of Numerical Analysis 191286 - 1304

Feldman J, Singh M, 2005 "Information along contours and object boundaries" Psychological Review $112243-252$

Gerr S, 1982 "A possible analogy between contours in mathematics - as exemplified by Cauchy's integral formula - and contours in the arts" Perception 11483 - 490

Gillebert C R, Op de Beeck H P, Ons B, Wagemans J, 2006 "The influence of categorisation on perceived shape similarity within natural object categories" Perception 35 Supplement, 35b

Grill-Spector K, Kushnir T, Edelman S, Itzchak Y, Malach R, 1998 "Cue-invariant activation in object-related areas of the human occipital lobe" Neuron $21191-202$

Hayward W G, 1998 "Effects of outline shape in object recognition" Journal of Experimental Psychology: Human Perception and Performance $24427-440$

Hayward W G, Tarr M J, Corderoy A K, 1999 "Recognizing silhouettes and shaded images across depth rotation" Perception 281197 - 1215

Hayward W G, Wong A C N, Spehar B, 2005 "When are viewpoint costs greater for silhouettes than for shaded images?" Psychonomic Bulletin and Review 12321 - 327 
Henson R N A, 2003 "Neuroimaging studies of priming" Progress in Neurobiology 70 53-81

Hoffman D D, Richards W A, 1984 "Parts of recognition" Cognition 18 65-96

Humphreys G W, Forde E M E, 2001 "Hierarchies, similarity, and interactivity in object recognition. 'Category-specific' neuropsychological deficits” Behavioral and Brain Sciences 24 453-476

Humphreys G W, Riddoch M J, Quinlan P T, 1988 "Cascade processes in picture identification" Cognitive Neuropsychology $567-103$

Jiang X, Bradley E, Rini R A, Zeffiro T, VanMeter J, Riesenhuber M, 2007 "Categorization training results in shape- and category-selective human neural plasticity" Neuron 53891 -903

Jolicoeur P, Gluck M A, Kosslyn S M, 1984 "Pictures and names: Making the connection" Cognitive Psychology $16243-275$

Kennedy J M, Domander R, 1985 "Shape and contour: The points of maximum change are least useful for recognition" Perception $14367-370$

Kennedy J M, Silver J, 1974 "The surrogate functions of lines in visual perception. Evidence from antipodal rock and cave artwork sources" Perception $3313-322$

Koenderink J J, Doorn A J van, 1982 "The shape of smooth objects and the way contours end" Perception 11 129-137

Koenderink J J, Doorn A J van, Christou C, Lappin J S, 1996 "Shape constancy in pictorial relief" Perception $25155-164$

Kourtzi Z, Kanwisher N, 2000 "Cortical regions involved in perceiving object shape" Journal of Neuroscience $203310-3318$

Kurbat M A, 1994 "Structural description theories: Is RBC/JIM a general-purpose theory of human entry-level object recognition?" Perception $231339-1369$

Lloyd-Jones T J, Humphreys G W, 1997 "Perceptual differentiation as a source of category effects in object processing: Evidence from naming and object decision" Memory \& Cognition 2518 - 35

Lloyd-Jones T J, Luckhurst L, 2002 "Outline shape is a mediator of object recognition that is particularly important for living things" Memory \& Cognition $30489-498$

Moore C, Engel S A, 2001 "Neural response to perception of volume in the lateral occipital complex" Neuron $29277-286$

Newell F N, Findlay J M, 1997 "The effect of depth rotation on object identification" Perception $261231-1257$

Norman J F, Phillips F, Ross H E, 2001 "Information concentration along the boundary contours of naturally shaped solid objects" Perception $301285-1294$

Norman J F, Raines S R, 2002 "The perception and discrimination of local 3-D surface structure from deforming and disparate boundary contours" Perception \& Psychophysics 641145 - 1159

Norman J F, Todd J T, 1994 "Perception of rigid motion in depth from the optical deformations of shadows and occlusion boundaries" Journal of Experimental Psychology: Human Perception and Performance $20343-356$

Nygård G, Wagemans J, 2005 "Perceptual grouping by proximity, similar orientation, and good continuation in outlines and surfaces derived from objects" Perception 34 Supplement, 127b

Op de Beeck H, Béatse E, Wagemans J, Sunaert S, Van Hecke P, 2000 "The representation of shape in the context of visual object categorisation tasks" NeuroImage $1228-40$

Op de Beeck H, Wagemans J, 2001 "Visual object categorization at distinct levels of abstraction: A new stimulus set" Perception $301337-1361$

Palmer S E, 1975 "The effects of contextual scenes on the identification of objects" Memory \& Cognition $3519-526$

Panis S, De Winter J, Vandekerckhove J, Wagemans J, 2008a "Identification of everyday objects on the basis of fragmented versions of outlines" Perception 37 271-289

Panis S, Vangeneugden J, Peeters R, Van Hecke P, Op de Beeck H, Wagemans J, 2005 "Perceived similarity between objects of the same category and prototypicality gradients in the lateral occipital complex", paper presented at the 35th Annual Meeting of the Society for Neuroscience, November, Washington, DC, USA; Abstract No. 620.11 published in 2005 Abstract Viewer/Itinerary Planner (On-line)

Panis S, Vangeneugden J, Wagemans J, 2008b "Similarity, typicality, and category-level matching of outlines of everyday objects" Perception submitted

Panis S, Wagemans J, 2008, "Time-course contingencies in perceptual organization and identification of fragmented object outlines" Journal of Experimental Psychology: Human Perception and Performance accepted

Rosch E, Mervis C B, Gray W D, Johnson D M, Boyes-Braem P, 1976 "Basic objects in natural categories" Cognitive Psychology $8382-439$

Rossion B, Pourtois G, 2004 "Revisiting Snodgrass and Vanderwart's object pictorial set: The role of surface detail in basic-level object recognition" Perception 33 217-236 
Sanocki T, Bowyer K W, Heath M D, Sarkar S, 1998 "Are edges sufficient for object recognition?" Journal of Experimental Psychology: Human Perception and Performance 24 340-349

Sereno M E, Trinath T, Augath M, Logothetis N K, 2002 "Three-dimensional shape representation in monkey cortex" Neuron 33 635-652

Severens E, Van Lommel S, Ratinckx E, Hartsuiker R J, 2005 "Timed picture naming norms for 590 pictures in Dutch" Acta Psychologica 119 159-187

Singh M, Seyranian G D, Hoffman D D, 1999 "Parsing silhouettes: The short-cut rule" Perception \& Psychophysics $61636-660$

Snodgrass J G, Vanderwart M, 1980 "A standardized set of 260 pictures: Norms for name agreement, image agreement, familiarity, and visual complexity" Journal of Experimental Psychology: Human Learning and Memory $6174-215$

Snodgrass J G, Yuditsky T, 1996 "Naming times for the Snodgrass and Vanderwart pictures" Behavior Research Methods, Instruments, and Computers 28 516-536

Thomas R, Forde E, 2006 "The role of local and global processing in the recognition of living and nonliving things" Neuropsychologia $44982-986$

Tjan B S, Braje W, Legge G E, Kersten D, 1995 "Human efficiency for recognizing 3-D objects in luminance noise" Vision Research $353053-3069$

Vangeneugden J, Wagemans J, 2004 "Perceptual representation of within-category similarity of everyday objects" Perception 33 Supplement, 74a

Verstijnen I, Wagemans J, 2004 "Ambiguous figures: Living versus nonliving objects" Perception $33531-546$

Wade N J, 2006 "Cave art interpretation 2" Perception 35 719-722

Wade N J, Melcher D, 2006 "Cave art interpretation 1" Perception 35 577-580

Wagemans J, Notebaert W, Boucart M, 1998 "Lorazepam but not diazepam impairs identification of pictures on the basis of specific contour fragments" Psychopharmacology 138 326-333

Wagemans J, Putzeys T, Pesce F, De Winter J, Brenner E, Smeets J, 2007 "Grasping points along the contour of outline drawings of everyday objects" Perception 36 Supplement, 7

Young M E, Peissig J J, Wasserman E A, Biederman I, 2001 "Discrimination of geons by pigeons: The effects of variations in surface depiction" Animal Learning and Behavior 29 97-106 
Table 1. Identification results from experiment 1 with silhouette and outline versions of the Snodgrass and Vanderwart (1980) pictures. Notes: The first two columns refer to the original numbers and names. $n$ is the number of subjects that were tested with each stimulus. 'Exact' refers to the number of subjects giving exactly the same name as in the Snodgrass and Vanderwart study (ie literal translation in Dutch). 'Other correct' refers to the numbers of subjects giving alternative names, reflecting the same concept (ordered from most to least frequent). 'Blank' refers to the number of subjects giving a blank response ("I do not know.") and 'Other incorrect' to the numbers of subjects for each of a number of alternative names that are considered incorrect. See text for more details about the scoring rules.

\begin{tabular}{|c|c|c|c|c|c|c|c|c|c|c|c|}
\hline \multirow[t]{2}{*}{ No } & \multirow[t]{2}{*}{ Name } & \multicolumn{5}{|c|}{ Silhouettes } & \multicolumn{5}{|c|}{ Outlines } \\
\hline & & $n$ & exact & other correct & blank & other incorrect & $\bar{n}$ & exact & other correct & blank & other incorrect \\
\hline 1 & accordion & 84 & 0 & 0 & 73 & $4,2,2,3(1)$ & 94 & 0 & 0 & 79 & $6,3,6(1)$ \\
\hline 2 & airplane & 87 & 87 & 0 & 0 & 0 & 89 & 86 & 1 & 2 & 0 \\
\hline 3 & alligator & 84 & 77 & 1 & 0 & $4,1,1$ & 94 & 78 & 5 & 0 & $9,1,1$ \\
\hline 4 & anchor & 87 & 87 & 0 & 0 & 0 & 89 & 85 & 0 & 2 & 1,1 \\
\hline 5 & ant & 87 & 69 & 5,2 & 1 & $3,2,5(1)$ & 89 & 52 & 9 & 12 & $4,4,3,5(1)$ \\
\hline 6 & apple & 87 & 86 & 0 & 0 & 1 & 89 & 88 & 0 & 1 & 0 \\
\hline 7 & arm & 87 & 83 & 3,1 & 0 & 0 & 89 & 87 & 0 & 1 & 1 \\
\hline 8 & arrow & 87 & 42 & 0 & 22 & 22,1 & 89 & 53 & 0 & 23 & $10,3(1)$ \\
\hline 9 & artichoke & 87 & 4 & 1 & 61 & $5,3,3(2), 7(1)$ & 89 & 0 & 0 & 59 & $5,3,3,5(2), 9(1)$ \\
\hline 10 & ashtray & 87 & 0 & 0 & 38 & $19,9,4,2,15(1)$ & 89 & 0 & 0 & 31 & $27,12,3,2,2,12(1)$ \\
\hline 11 & asparagus & 87 & 1 & 0 & 56 & $9,3,3,3(2), 9(1)$ & 89 & 2 & 0 & 64 & $6,5,3,2,7(1)$ \\
\hline 12 & axe & 87 & 76 & $3,1,1$ & 0 & 6 & 89 & 81 & $3,1,1$ & 1 & 2 \\
\hline 13 & baby carriage & 87 & 56 & $10,7,5,3,5(1)$ & 0 & 1 & 89 & 70 & $10,6,2$ & 1 & 0 \\
\hline 14 & ball & 87 & 52 & 1,1 & 5 & $9,7,4(2), 4(1)$ & 89 & 48 & 0 & 2 & $17,7,4,3,2,2,4(1)$ \\
\hline 15 & balloon & 87 & 86 & 1 & 0 & 0 & 89 & 86 & 0 & 0 & $3(1)$ \\
\hline 16 & banana & 87 & 85 & 0 & 0 & 1,1 & 89 & 86 & 0 & 0 & 3 \\
\hline 17 & barn & 84 & 1 & 2,1 & 61 & $4,3,3,2,7(1)$ & 94 & 0 & 3,1 & 55 & $8,5,5,4,3(2), 7(1)$ \\
\hline 18 & barrel & 87 & 55 & $7,3,1$ & 13 & $4,4(1)$ & 89 & 29 & 1 & 31 & $8,7,2,2,9(1)$ \\
\hline 19 & baseball bat & 84 & 15 & $13,11,7,6,6,3,3,2,2,1$ & 6 & $2,7(1)$ & 94 & 24 & $16,14,8,6,3(3), 1$ & 11 & $5(1)$ \\
\hline 20 & basket & 87 & 0 & $3,2,1$ & 51 & $11,8,11(1)$ & 89 & 8 & 0 & 54 & $18,2,7(1)$ \\
\hline 21 & bear & 87 & 74 & $10,1,1$ & 0 & 1 & 89 & 66 & 21 & 1 & 1 \\
\hline 22 & bed & 84 & 83 & 1 & 0 & 0 & 94 & 91 & 2,1 & 0 & 0 \\
\hline 23 & bee & 87 & 4 & $23,3(1)$ & 1 & $30,7,5,4,10(1)$ & 89 & 4 & 28,3 & 9 & $20,5,4,3,3(2), 7(1)$ \\
\hline 24 & beetle & 87 & 69 & $5,5,1,1$ & 2 & $2,1,1$ & 89 & 53 & 11,3 & 7 & $3,3,9(1)$ \\
\hline 25 & bell & 87 & 45 & $22,10,1$ & 0 & 8,1 & 89 & 56 & 32 & 1 & 0 \\
\hline 26 & belt & 87 & 0 & 0 & 64 & $3,3,3(2), 11(1)$ & 89 & 0 & 0 & 76 & $3(2), 7(1)$ \\
\hline 27 & bicycle & 87 & 81 & $3(1)$ & 0 & 2,1 & 89 & 68 & 0 & 0 & $13,7,1$ \\
\hline 28 & bird & 87 & 80 & $4,1,1$ & 1 & 0 & 89 & 82 & $5,1,1$ & 0 & 0 \\
\hline 29 & blouse & 87 & 4 & 2 & 0 & $39,24,9,2,2,5(1)$ & 89 & 6 & 5 & 0 & $44,23,9,1,1$ \\
\hline
\end{tabular}


Table 1 (continued)

\begin{tabular}{|c|c|c|c|c|c|c|c|c|c|c|c|}
\hline \multirow[t]{2}{*}{ No } & \multirow[t]{2}{*}{ Name } & \multicolumn{5}{|c|}{ Silhouettes } & \multicolumn{5}{|c|}{ Outlines } \\
\hline & & $n$ & exact & other correct & blank & other incorrect & $n$ & exact & other correct & blank & other incorrect \\
\hline 30 & book & 84 & 11 & 0 & 66 & $2,2,3(1)$ & 94 & 1 & 0 & 85 & $2,6(1)$ \\
\hline 31 & boot & 84 & 77 & $3,2,1,1$ & 0 & 0 & 94 & 87 & 4,2 & 0 & 1 \\
\hline 32 & bottle & 87 & 75 & $4,3,2,3(1)$ & 0 & 0 & 89 & 84 & 3,2 & 0 & 0 \\
\hline 33 & bow & 84 & 82 & 2 & 0 & 0 & 94 & 85 & $5(1)$ & 0 & 3,1 \\
\hline 34 & bowl & 87 & 65 & $4,2,2,1,1$ & 2 & $10(1)$ & 89 & 77 & 3 & 4 & $5(1)$ \\
\hline 35 & box & 87 & 3 & $2,2,1,1$ & 39 & $12,6,5,4,3,2,7(1)$ & 89 & 0 & 0 & 59 & $8,8,3(2), 8(1)$ \\
\hline 36 & bread & 84 & 35 & 0 & 17 & $24,2,6(1)$ & 94 & 40 & 1 & 21 & $19,4,9(1)$ \\
\hline 37 & broom & 84 & 22 & $6,2,1,1$ & 0 & $31,9,7,5(1)$ & 94 & 11 & 4 & 0 & $44,22,6,3,2,1,1$ \\
\hline 38 & brush & 84 & 52 & 11,8 & 4 & $3,2,4(1)$ & 94 & 26 & $7,6,5,6(1)$ & 2 & $8,4,3(3), 3(2), 15(1)$ \\
\hline 39 & bus & 87 & 30 & 14,1 & 12 & $6,6,5,4,2,2,5(1)$ & 89 & 35 & 20 & 17 & $5,3,2,7(1)$ \\
\hline 40 & butterfly & 84 & 84 & 0 & 0 & 0 & 94 & 94 & 0 & 0 & 0 \\
\hline 41 & button & 84 & 0 & 0 & 0 & $64,6,4,3(2), 4(1)$ & 94 & 0 & 0 & 1 & $56,11,5,3,3,3(2), 9(1)$ \\
\hline 42 & cake & 87 & 0 & 0 & 1 & $84,1,1$ & 89 & 0 & 0 & 5 & $80,4(1)$ \\
\hline 43 & camel & 84 & 60 & 22,1 & 0 & 1 & 94 & 62 & 28,2 & 1 & 1 \\
\hline 44 & candle & 84 & 83 & 0 & 1 & 0 & 94 & 87 & 1 & 2 & $4(1)$ \\
\hline 45 & cannon & 87 & 4 & 0 & 70 & $2,11(1)$ & 89 & 14 & 0 & 65 & $2,8(1)$ \\
\hline 46 & cap & 84 & 7 & 1 & 46 & $15,5,4,3,3(1)$ & 94 & 3 & 0 & 69 & $8,3,2,2,7(1)$ \\
\hline 47 & car & 84 & 82 & 2 & 0 & 0 & 94 & 94 & 0 & 0 & 0 \\
\hline 48 & carrot & 87 & 85 & 0 & 0 & 1,1 & 89 & 89 & 0 & 0 & 0 \\
\hline 49 & cat & 84 & 61 & 21,2 & 0 & 0 & 94 & 54 & 36,4 & 0 & 0 \\
\hline 50 & caterpillar & 87 & 52 & 14,1 & 12 & $5,3(1)$ & 89 & 55 & 10 & 17 & $4,3(1)$ \\
\hline 51 & celery & 84 & 43 & 5 & 4 & $20,3(2), 6(1)$ & 94 & 41 & $2,3(1)$ & 8 & $29,6,2,3(1)$ \\
\hline 52 & chain & 84 & 7 & $6,3,1,1$ & 20 & $29,7,2,8(1)$ & 94 & 6 & $3,2,1$ & 25 & $30,10,4,3,2,8(1)$ \\
\hline 53 & chair & 84 & 80 & 3,1 & 0 & 0 & 94 & 89 & $3,1,1$ & 0 & 0 \\
\hline 54 & cherry & 84 & 80 & 3 & 0 & 1 & 94 & 83 & 6,1 & 1 & $3(1)$ \\
\hline 55 & chicken & 87 & 84 & 2 & 0 & 1 & 89 & 87 & 1,1 & 0 & 0 \\
\hline 56 & chisel & 87 & 13 & 1 & 39 & $8,8,3,2,2,11(1)$ & 89 & 4 & 0 & 51 & $11,5,4,3,2,9(1)$ \\
\hline 57 & church & 84 & 78 & 1 & 0 & 5 & 94 & 90 & 3 & 0 & 1 \\
\hline 58 & cigar & 84 & 4 & 0 & 4 & $44,11,4(3), 2,2,5(1)$ & 94 & 2 & 0 & 8 & $43,3(6), 3,3,3(2), 11(1)$ \\
\hline 59 & cigarette & 84 & 61 & 2,2 & 6 & $4,2,2,5(1)$ & 94 & 63 & $3,1,1$ & 11 & $7,3,5(1)$ \\
\hline 60 & clock & 87 & 1 & 0 & 49 & $5,5,4,4,3,16(1)$ & 89 & 2 & 0 & 51 & $6,5,5,4,3(2), 10(1)$ \\
\hline 61 & clothespin & 84 & 60 & $10,1,1$ & 6 & $3,2,1$ & 94 & 59 & 15 & 7 & $5,2,6(1)$ \\
\hline 62 & cloud & 87 & 2 & 0 & 61 & $6,3,2,13(1)$ & 89 & 2 & 0 & 66 & $4,3,2,2,10(1)$ \\
\hline 63 & clown & 84 & 0 & 0 & 57 & $6,4,2,2,13(1)$ & 94 & 1 & 0 & 69 & $9,15(1)$ \\
\hline
\end{tabular}


Table 1 (continued)

\begin{tabular}{|c|c|c|c|c|c|c|c|c|c|c|c|}
\hline \multirow[t]{2}{*}{ No } & \multirow[t]{2}{*}{ Name } & \multicolumn{5}{|c|}{ Silhouettes } & \multicolumn{5}{|c|}{ Outlines } \\
\hline & & $n$ & exact & other correct & blank & other incorrect & $n$ & exact & other correct & blank & other incorrect \\
\hline 64 & coat & 84 & 57 & $9,4,1$ & 0 & $7,6(1)$ & 94 & 62 & $11,5,2,1,1$ & 0 & $3,2,2,5(1)$ \\
\hline 65 & comb & 84 & 84 & 0 & 0 & 0 & 94 & 92 & 2 & 0 & 0 \\
\hline 66 & corn & 87 & 2 & 4 & 67 & $2,2,10(1)$ & 89 & 6 & 0 & 59 & $6,5,2,11(1)$ \\
\hline 67 & couch & 84 & 55 & $9,9,7,3(1)$ & 0 & 1 & 94 & 64 & $7,7,5,3,5(1)$ & 1 & 2 \\
\hline 68 & cow & 84 & 72 & $10,1,1$ & 0 & 0 & 94 & 82 & $8,1,1$ & 2 & 0 \\
\hline 69 & crown & 87 & 60 & 0 & 6 & $9,5,2,5(1)$ & 89 & 48 & 0 & 13 & $18,9,1$ \\
\hline 70 & cup & 84 & 28 & $34,11,1,1$ & 6 & $3(1)$ & 94 & 36 & $24,4,3,10(1)$ & 17 & 0 \\
\hline 71 & deer & 87 & 82 & $5(1)$ & 0 & 0 & 89 & 86 & 3 & 0 & 0 \\
\hline 72 & desk & 87 & 21 & 1,1 & 21 & $19,12,5,3,4(1)$ & 89 & 1 & 0 & 54 & $14,9,3,2,6(1)$ \\
\hline 73 & $\operatorname{dog}$ & 84 & 84 & 0 & 0 & 0 & 94 & 94 & 0 & 0 & 0 \\
\hline 74 & doll & 87 & 61 & $3,2,2$ & 0 & $13,4,1,1$ & 89 & 61 & 0 & 0 & $26,1,1$ \\
\hline 75 & donkey & 84 & 83 & 1 & 0 & 0 & 94 & 86 & 0 & 1 & $5,1,1$ \\
\hline 76 & door & 87 & 5 & 1,1 & 63 & $3,3(2), 8(1)$ & 89 & 7 & 0 & 60 & $5,5,2,2,8(1)$ \\
\hline 77 & doorknob & 84 & 12 & 0 & 27 & $13,11,7,3,3,2,6(1)$ & 94 & 23 & 2,1 & 36 & $7,6,6,3(2), 7(1)$ \\
\hline 78 & dress & 87 & 46 & $35,4,2$ & 0 & 0 & 89 & 53 & 34 & 2 & 0 \\
\hline 79 & dresser & 84 & 67 & $3(2), 1$ & 3 & $3,2,1,1$ & 94 & 51 & $3,5(1)$ & 23 & $2,2,8(1)$ \\
\hline 80 & drum & 87 & 7 & 0 & 43 & $4,4(3), 3(2), 15(1)$ & 89 & 2 & 0 & 49 & $7,4,3,3,5(2), 11(1)$ \\
\hline 81 & duck & 84 & 83 & 0 & 0 & 1 & 94 & 91 & 1 & 0 & 2 \\
\hline 82 & eagle & 84 & 30 & $6,2,1$ & 0 & $18,10,8,5,2,1,1$ & 94 & 31 & $10,1,1$ & 1 & $16,16,9,5,3,1$ \\
\hline 83 & ear & 84 & 7 & 0 & 57 & $5,4,3,3,5(1)$ & 94 & 1 & 0 & 69 & $7,5,3(2), 6(1)$ \\
\hline 84 & elephant & 84 & 84 & 0 & 0 & 0 & 94 & 94 & 0 & 0 & 0 \\
\hline 85 & envelope & 87 & 0 & 0 & 47 & $6,5,4,3(3), 2,14(1)$ & 89 & 0 & 0 & 50 & $11,5,5,3,3,3(2), 6(1)$ \\
\hline 86 & eye & 87 & 1 & 0 & 3 & $37,14,9,7,5,3,2,6(1)$ & 89 & 0 & 0 & 6 & $76,4,3(1)$ \\
\hline 87 & fence & 84 & 76 & $5(1)$ & 0 & $3(1)$ & 94 & 57 & $6,3,2,4(1)$ & 9 & $4,2,7(1)$ \\
\hline 88 & finger & 84 & 38 & $22,5,1$ & 15 & $3(1)$ & 94 & 18 & $17,6,7(1)$ & 31 & $9,3,3(1)$ \\
\hline 89 & fish & 84 & 81 & 2 & 0 & 1 & 94 & 94 & 0 & 0 & 0 \\
\hline 90 & flag & 87 & 84 & 3 & 0 & 0 & 89 & 88 & 0 & 0 & 1 \\
\hline 91 & flower & 84 & 82 & 1,1 & 0 & 0 & 94 & 93 & 1 & 0 & 0 \\
\hline 92 & flute & 87 & 14 & 6,1 & 42 & $4,3,2,15(1)$ & 89 & 12 & 0 & 53 & $6,5,3,3,2,2,3(1)$ \\
\hline 93 & fly & 84 & 73 & 9,1 & 0 & 1 & 94 & 78 & $9,1,1$ & 1 & $4(1)$ \\
\hline 94 & foot & 84 & 83 & 0 & 0 & 1 & 94 & 80 & $2,1,1$ & 0 & $6,2,2$ \\
\hline 95 & football & 84 & 37 & 2,1 & 4 & $13,9,6,2,2,8(1)$ & 94 & 16 & 0 & 5 & $48,16,3,2,4(1)$ \\
\hline 96 & football helmet & 84 & 59 & $3,3,2,1$ & 15 & 1 & 94 & 59 & $2,4(1)$ & 26 & $3(1)$ \\
\hline 97 & fork & 84 & 84 & 0 & 0 & 0 & 94 & 94 & 0 & 0 & 0 \\
\hline
\end{tabular}


Table 1 (continued)

\begin{tabular}{|c|c|c|c|c|c|c|c|c|c|c|c|}
\hline \multirow[t]{2}{*}{ No } & \multirow[t]{2}{*}{ Name } & \multicolumn{5}{|c|}{ Silhouettes } & \multicolumn{5}{|c|}{ Outlines } \\
\hline & & $n$ & exact & other correct & blank & other incorrect & $n$ & exact & other correct & blank & other incorrect \\
\hline 98 & fox & 87 & 78 & 1 & 0 & 5,3 & 89 & 81 & 0 & 0 & 7,1 \\
\hline 99 & French horn & 87 & 45 & $12,5,3(2), 9(1)$ & 3 & 7 & 89 & 39 & $16,7,5,4,3,3,1,1$ & 0 & 10 \\
\hline 100 & frog & 87 & 86 & 1 & 0 & 0 & 89 & 83 & 6 & 0 & 0 \\
\hline 101 & frying pan & 87 & 1 & $68,3(2), 1,1$ & 5 & $2,3(1)$ & 89 & 2 & $58,4,2,1$ & 12 & $3,2,2,3(1)$ \\
\hline 102 & garbage can & 87 & 42 & $17,9,1$ & 13 & $5(1)$ & 89 & 25 & 34 & 15 & $4,3,2,6(1)$ \\
\hline 103 & giraffe & 87 & 87 & 0 & 0 & 0 & 89 & 89 & 0 & 0 & 0 \\
\hline 104 & glass & 87 & 42 & $7,3,2,1,1$ & 6 & $13,12(1)$ & 89 & 76 & 3 & 1 & $4,2,3(1)$ \\
\hline 105 & glasses & 87 & 75 & $9,2,1$ & 0 & 0 & 89 & 88 & 1 & 0 & 0 \\
\hline 106 & glove & 84 & 64 & 0 & 0 & 20 & 94 & 59 & 2 & 1 & 32 \\
\hline 107 & goat & 84 & 68 & $7,1,1$ & 1 & $2,4(1)$ & 94 & 65 & $14,1,1$ & 0 & $3,3(2), 4(1)$ \\
\hline 108 & gorilla & 87 & 41 & $34,8,1,1$ & 0 & 1,1 & 89 & 55 & 27 & 1 & $4,1,1$ \\
\hline 109 & grapes & 84 & 23 & 10,1 & 5 & $40,2,3(1)$ & 94 & 19 & $16,8,1,1$ & 3 & $33,5,2,2,4(1)$ \\
\hline 110 & grasshopper & 87 & 20 & 24,1 & 12 & $8,6,4,2,10(1)$ & 89 & 11 & 24 & 35 & $5,3,2,2,7(1)$ \\
\hline 111 & guitar & 87 & 87 & 0 & 0 & 0 & 89 & 89 & 0 & 0 & 0 \\
\hline 112 & gun & 84 & 40 & 31 & 0 & 13 & 94 & 37 & 37 & 0 & 20 \\
\hline 113 & hair & 84 & 0 & 0 & 54 & $11,10,2,2,5(1)$ & 94 & 0 & 0 & 79 & $5,10(1)$ \\
\hline 114 & hammer & 87 & 83 & $3(1)$ & 1 & 0 & 89 & 87 & 1 & 1 & 0 \\
\hline 115 & hand & 87 & 77 & 2 & 0 & 8 & 89 & 63 & 0 & 0 & 25,1 \\
\hline 116 & hanger & 87 & 20 & 66,1 & 0 & 0 & 89 & 20 & 67,2 & 0 & 0 \\
\hline 117 & harp & 84 & 71 & 1 & 8 & $2,1,1$ & 94 & 70 & 0 & 22 & 1,1 \\
\hline 118 & hat & 84 & 84 & 0 & 0 & 0 & 94 & 93 & 0 & 0 & 1 \\
\hline 119 & heart & 87 & 79 & 7,1 & 0 & 0 & 89 & 89 & 0 & 0 & 0 \\
\hline 120 & helicopter & 84 & 84 & 0 & 0 & 0 & 94 & 93 & 0 & 0 & 1 \\
\hline 121 & horse & 84 & 83 & 1 & 0 & 0 & 94 & 94 & 0 & 0 & 0 \\
\hline 122 & house & 87 & 9 & 1,1 & 71 & $5(1)$ & 89 & 24 & 0 & 52 & $3,2,8(1)$ \\
\hline 123 & iron & 87 & 21 & 0 & 14 & $33,4,4,2,9(1)$ & 89 & 47 & 0 & 21 & $11,5,2,3(1)$ \\
\hline 124 & iron board & 84 & 3 & 0 & 71 & 10 & 94 & 72 & 1 & 2 & $10,3,3,3(1)$ \\
\hline 125 & jacket & 87 & 4 & 61,8 & 0 & $5(2), 4(1)$ & 89 & 10 & 54,12 & 8 & $5(1)$ \\
\hline 126 & kangaroo & 84 & 82 & 1 & 1 & 0 & 94 & 94 & 0 & 0 & 0 \\
\hline 127 & kettle & 84 & 12 & $16,11,4,3,2,2,1,1$ & 30 & 1,1 & 94 & 17 & $15,6,2(5), 4,3,5(1)$ & 26 & $4,2,1,1$ \\
\hline 128 & key & 87 & 86 & 1 & 0 & 0 & 89 & 88 & 0 & 0 & 1 \\
\hline 129 & kite & 87 & 72 & $9,2,1,1$ & 2 & 0 & 89 & 87 & 1,1 & 0 & 0 \\
\hline 130 & knife & 87 & 49 & 1 & 20 & $5,2,10(1)$ & 89 & 68 & 0 & 12 & $3(2), 3(1)$ \\
\hline 131 & ladder & 84 & 1 & 0 & 20 & $31,9,3,4(2), 12(1)$ & 94 & 4 & 0 & 27 & $22,15,3,4(2), 15(1)$ \\
\hline
\end{tabular}


Table 1 (continued)

\begin{tabular}{|c|c|c|c|c|c|c|c|c|c|c|c|}
\hline \multirow[t]{2}{*}{ No } & \multirow[t]{2}{*}{ Name } & \multicolumn{5}{|c|}{ Silhouettes } & \multicolumn{5}{|c|}{ Outlines } \\
\hline & & $n$ & exact & other correct & blank & other incorrect & $n$ & exact & other correct & blank & other incorrect \\
\hline 132 & lamp & 84 & 65 & $9,3,2,5(1)$ & 0 & 0 & 94 & 64 & $6,5,3,3,3(2), 7(1)$ & 0 & 0 \\
\hline 133 & leaf & 84 & 62 & $9,9,4(1)$ & 0 & 0 & 94 & 70 & $8,4,3(3), 3(1)$ & 0 & 0 \\
\hline 134 & leg & 84 & 80 & 3,1 & 0 & 0 & 94 & 91 & $3(1)$ & 0 & 0 \\
\hline 135 & lemon & 87 & 81 & 0 & 0 & 4,2 & 89 & 83 & 0 & 0 & $2,4(1)$ \\
\hline 136 & leopard & 84 & 3 & 28,2 & 0 & $29,11,5,3,2,1$ & 94 & 6 & $13,3(1)$ & 1 & $40,11,8,5,3,2,1,1$ \\
\hline 137 & lettuce & 87 & 4 & 2,1 & 29 & $19,5,4(3), 3(2), 9(1)$ & 89 & 8 & 1 & 42 & $7,5,5,3,3,2,2,11(1)$ \\
\hline 138 & light bulb & 84 & 19 & 51 & 6 & $4,3,1$ & 94 & 26 & $52,2,2(1)$ & 5 & $7(1)$ \\
\hline 139 & light switch & 84 & 0 & 0 & 29 & $27,9,6,3,2,2,6(1)$ & 94 & 0 & 0 & 44 & $6,5,4(4), 5(2), 13(1)$ \\
\hline 140 & lion & 84 & 82 & 0 & 0 & 2 & 94 & 94 & 0 & 0 & 0 \\
\hline 141 & lips & 87 & 47 & $30,8,1$ & 0 & 1 & 89 & 50 & $25,9,3,1$ & 1 & 0 \\
\hline 142 & lobster & 87 & 79 & 0 & 0 & 4,4 & 89 & 81 & 1 & 5 & 2 \\
\hline 143 & lock & 87 & 50 & $28,2,2,3(1)$ & 1 & 1 & 89 & 48 & $31,3,2,3(1)$ & 0 & 2 \\
\hline 144 & mitten & 84 & 49 & 34,1 & 0 & 0 & 94 & 47 & 43,3 & 0 & 0 \\
\hline 145 & monkey & 87 & 62 & 22,3 & 0 & 0 & 89 & 84 & 4,1 & 0 & 0 \\
\hline 146 & moon & 87 & 71 & $8,3(2), 1,1$ & 0 & 0 & 89 & 81 & $4,3,1$ & 0 & 0 \\
\hline 147 & motorcycle & 87 & 20 & $21,20,10,8,4,4(1)$ & 0 & 0 & 89 & 25 & $24,17,11,9,2,1$ & 0 & 0 \\
\hline 148 & mountain & 84 & 26 & $7,7,4,2,5(1)$ & 15 & $8,3(2), 4(1)$ & 94 & 19 & $21,4,2,2,2,5(1)$ & 24 & $6,2,7(1)$ \\
\hline 149 & mouse & 84 & 69 & 0 & 0 & 15 & 94 & 78 & $5,3(1)$ & 0 & 8 \\
\hline 150 & mushroom & 84 & 82 & 1,1 & 0 & 0 & 94 & 93 & 0 & 0 & 1 \\
\hline 151 & nail & 87 & 25 & 38 & 0 & $5,5(2), 9(1)$ & 89 & 13 & 38 & 4 & $6,5,5,4,4,2,2,6(1)$ \\
\hline 152 & nail file & 84 & 0 & 1 & 4 & $30,17,9,6,5,3,2,2,5(1)$ & 94 & 1 & 1,1 & 17 & $29,10,9,4,3(3), 2,11(1)$ \\
\hline 153 & necklace & 84 & 0 & 0 & 56 & $4,4,3(3), 3(2), 5(1)$ & 94 & 0 & 0 & 48 & $17,5,4,3,3,3(2), 8(1)$ \\
\hline 154 & needle & 84 & 41 & $4,3(1)$ & 11 & $7,4(3), 6(1)$ & 94 & 53 & $2,1,1$ & 12 & $9,4,3,2,2,5(1)$ \\
\hline 155 & nose & 87 & 3 & 0 & 39 & $15,7,4,2,17(1)$ & 89 & 2 & 0 & 51 & $14,6,3,5(2), 3(1)$ \\
\hline 156 & nut & 84 & 0 & 0 & 56 & $8,3,2,2,13(1)$ & 94 & 0 & 0 & 71 & $6,3(2), 11(1)$ \\
\hline 157 & onion & 84 & 35 & 39,1 & 0 & $2,7(1)$ & 94 & 49 & 28,1 & 6 & $3,7(1)$ \\
\hline 158 & orange & 84 & 12 & 8 & 7 & $46,3(2), 5(1)$ & 94 & 14 & 12 & 13 & $29,4,3,4(2), 11(1)$ \\
\hline 159 & ostrich & 87 & 80 & 0 & 0 & $2,2,3(1)$ & 89 & 81 & 0 & 1 & $2,2,3(1)$ \\
\hline 160 & owl & 84 & 64 & 0 & 14 & $2,4(1)$ & 94 & 64 & 0 & 13 & $3,2,2,10(1)$ \\
\hline 161 & paintbrush & 87 & 79 & 4 & 0 & 3,1 & 89 & 69 & 0 & 0 & $9,8,3(1)$ \\
\hline 162 & pants & 87 & 85 & 2 & 0 & 0 & 89 & 89 & 0 & 0 & 0 \\
\hline 163 & peach & 87 & 0 & 0 & 8 & $35,16,11,4,3,10(1)$ & 89 & 1 & 0 & 3 & $21,19,17,6,4,3,4(2), 7(1)$ \\
\hline 164 & peacock & 87 & 81 & 0 & 0 & $3,3(1)$ & 89 & 88 & 0 & 0 & 1 \\
\hline 165 & peanut & 84 & 23 & $17,16,5$ & 13 & $4,2,4(1)$ & 94 & 11 & $11,9,5,5,4,2$ & 26 & $8,2,2,8(1)$ \\
\hline
\end{tabular}


Table 1 (continued)

\begin{tabular}{|c|c|c|c|c|c|c|c|c|c|c|c|}
\hline \multirow[t]{2}{*}{ No } & \multirow[t]{2}{*}{ Name } & \multicolumn{5}{|c|}{ Silhouettes } & \multicolumn{5}{|c|}{ Outlines } \\
\hline & & $n$ & exact & other correct & blank & other incorrect & $n$ & exact & other correct & blank & other incorrect \\
\hline 166 & pear & 87 & 87 & 0 & 0 & 0 & 89 & 89 & 0 & 0 & 0 \\
\hline 167 & pen & 84 & 36 & $34,9,4$ & 0 & 1 & 94 & 44 & $24,6,6,3(1)$ & 4 & $3,2,1,1$ \\
\hline 168 & pencil & 84 & 14 & 1 & 28 & $17,8,4,2,10(1)$ & 94 & 18 & 1 & 38 & $19,6,2,10(1)$ \\
\hline 169 & penguin & 87 & 86 & 0 & 1 & 0 & 89 & 88 & 0 & 0 & 1 \\
\hline 170 & pepper & 84 & 4 & 0 & 70 & $2,2,6(1)$ & 94 & 7 & 0 & 75 & $3,2,7(1)$ \\
\hline 171 & piano & 84 & 45 & 38 & 1 & 0 & 94 & 52 & 36,1 & 4 & 1 \\
\hline 172 & pig & 87 & 77 & $4,2,3(1)$ & 0 & 1 & 89 & 76 & 4,2 & 0 & 7 \\
\hline 173 & pineapple & 87 & 86 & 0 & 1 & 0 & 89 & 87 & 0 & 0 & 1,1 \\
\hline 174 & pipe & 84 & 83 & 0 & 1 & 0 & 94 & 94 & 0 & 0 & 0 \\
\hline 175 & pitcher & 87 & 36 & $10,4,4(2), 6(1)$ & 17 & $2,4(1)$ & 89 & 42 & $7,4,2,3(1)$ & 25 & $6(1)$ \\
\hline 176 & pliers & 87 & 55 & $14,10,3,3(1)$ & 0 & 1,1 & 89 & 54 & $17,12,3,2,1$ & 0 & 0 \\
\hline 177 & plug & 87 & 77 & $4(1)$ & 5 & 1 & 89 & 65 & 2 & 15 & $2,2,3(1)$ \\
\hline 178 & pocketbook & 87 & 0 & 0 & 57 & $10,5,3,3,2,7(1)$ & 89 & 0 & 2 & 58 & $6,4,3(2), 13(1)$ \\
\hline 179 & pot & 84 & 13 & $33,10,9,6,6$ & 4 & $3(1)$ & 94 & 9 & $24,3(7), 4,2,3(1)$ & 17 & $4,10(1)$ \\
\hline 180 & potato & 87 & 9 & 0 & 37 & $10,8,7,5,3,2,6(1)$ & 89 & 12 & 0 & 53 & $9,3,2,2,8(1)$ \\
\hline 181 & pumpkin & 84 & 2 & 0 & 0 & $73,6,3$ & 94 & 1 & 0 & 1 & $73,6,4,4,6(1)$ \\
\hline 182 & rabbit & 87 & 84 & 2 & 0 & 1 & 89 & 88 & 0 & 0 & 1 \\
\hline 183 & raccoon & 87 & 23 & $3,2,2,1,1$ & 8 & $11,8,4,4,3,2,2,13(1)$ & 89 & 7 & 0 & 9 & $24,22,7,6,6,3,2,2,1$ \\
\hline 184 & record player & 84 & 0 & 0 & 46 & $14,4,3(2), 14(1)$ & 94 & 0 & 0 & 78 & $5,2,9(1)$ \\
\hline 185 & refrigerator & 84 & 1 & 0 & 27 & $16,16,6,4,3,2,2,7(1)$ & 94 & 1 & 2 & 35 & $6,4(5), 3(4), 4(2), 10(1)$ \\
\hline 186 & rhinoceros & 84 & 82 & 1 & 0 & 1 & 94 & 87 & 1 & 1 & 5 \\
\hline 187 & ring & 84 & 0 & 0 & 54 & $11,3,16(1)$ & 94 & 1 & 1 & 57 & $8,4,4,3,2,14(1)$ \\
\hline 188 & rocking chair & 87 & 66 & $6,5,3(2), 1,1$ & 2 & 0 & 89 & 74 & $3,5(1)$ & 6 & 1 \\
\hline 189 & roller skate & 84 & 51 & 0 & 19 & $3,11(1)$ & 94 & 27 & 0 & 52 & $3,2,10(1)$ \\
\hline 190 & rolling pin & 87 & 76 & 7,1 & 2 & 1 & 89 & 87 & 0 & 1 & 1 \\
\hline 191 & rooster & 87 & 76 & 1 & 0 & 10 & 89 & 81 & 0 & 0 & 8 \\
\hline 192 & ruler & 84 & 1 & 0 & 54 & $9,5,3,2,10(1)$ & 94 & 3 & 2 & 63 & $5,4,2,15(1)$ \\
\hline 193 & sailboat & 84 & 44 & $17,9,9,2,1,1$ & 1 & 0 & 94 & 71 & $14,2,4(1)$ & 0 & 2,1 \\
\hline 194 & saltshaker & 84 & 6 & 2,1 & 32 & $19,6,4,3,2,9(1)$ & 94 & 1 & 1,1 & 36 & $17,10,8,5,3,2,2,8(1)$ \\
\hline 195 & sandwich & 84 & 1 & 1 & 63 & $3(3), 2,2,6(1)$ & 94 & 1 & 1,1 & 78 & $3,2,8(1)$ \\
\hline 196 & saw & 84 & 56 & 0 & 15 & $5,2,6(1)$ & 94 & 58 & 0 & 17 & $11,8(1)$ \\
\hline 197 & scissors & 84 & 84 & 0 & 0 & 0 & 94 & 93 & 0 & 1 & 0 \\
\hline 198 & screw & 87 & 37 & $26,4(1)$ & 0 & $8,3,3,2,4(1)$ & 89 & 39 & 27 & 6 & $8,7,1,1$ \\
\hline 199 & screwdriver & 87 & 84 & 2,1 & 0 & 0 & 89 & 87 & 0 & 1 & 1 \\
\hline
\end{tabular}


Table 1 (continued)

\begin{tabular}{|c|c|c|c|c|c|c|c|c|c|c|c|}
\hline \multirow[t]{2}{*}{ No } & \multirow[t]{2}{*}{ Name } & \multicolumn{5}{|c|}{ Silhouettes } & \multicolumn{5}{|c|}{ Outlines } \\
\hline & & $\bar{n}$ & exact & other correct & blank & other incorrect & $n$ & exact & other correct & blank & other incorrect \\
\hline 200 & sea horse & 84 & 57 & 27 & 0 & 0 & 94 & 66 & 25,1 & 2 & 0 \\
\hline 201 & seal & 84 & 65 & $5,4,4,3$ & 2 & 1 & 94 & 74 & $7,4,3,1$ & 2 & $3(1)$ \\
\hline 202 & sheep & 87 & 69 & 1,1 & 1 & $7,2,2,4(1)$ & 89 & 59 & 1 & 3 & $13,7,6(1)$ \\
\hline 203 & shirt & 87 & 49 & $2,1,1$ & 0 & $23,10,1$ & 89 & 48 & 6 & 1 & $21,5,2,6(1)$ \\
\hline 204 & shoe & 84 & 84 & 0 & 0 & 0 & 94 & 94 & 0 & 0 & 0 \\
\hline 205 & skirt & 84 & 66 & 0 & 5 & $8,2,3(1)$ & 94 & 38 & 1,1 & 27 & $12,4,3,3,2,3(1)$ \\
\hline 206 & skunk & 84 & 7 & 0 & 2 & $72,2,1$ & 94 & 9 & 1,1 & 5 & $70,2,6(1)$ \\
\hline 207 & sled & 84 & 1 & 0 & 53 & $9,4,2,15(1)$ & 94 & 1 & 0 & 80 & $3,2,2,6(1)$ \\
\hline 208 & snail & 87 & 87 & 0 & 0 & 0 & 89 & 89 & 0 & 0 & 0 \\
\hline 209 & snake & 84 & 83 & 0 & 0 & 1 & 94 & 93 & 0 & 0 & 1 \\
\hline 210 & snowman & 87 & 84 & 2,1 & 0 & 0 & 89 & 89 & 0 & 0 & 0 \\
\hline 211 & sock & 87 & 52 & $31,1,1$ & 0 & 1,1 & 89 & 60 & 29 & 0 & 0 \\
\hline 212 & spider & 84 & 80 & 1 & 1 & 1,1 & 94 & 88 & $4(1)$ & 2 & 0 \\
\hline 213 & spinning wheel & 84 & 0 & 0 & 32 & $42,6,4(1)$ & 94 & 0 & 0 & 47 & $33,10,4(1)$ \\
\hline 214 & spool of thread & 87 & 2 & $4,2,2,10(1)$ & 41 & $4,3,3,16(1)$ & 89 & 1 & 8,1 & 44 & $7,5,5(2), 13(1)$ \\
\hline 215 & spoon & 84 & 78 & $4,1,1$ & 0 & 0 & 94 & 84 & $6,2,1,1$ & 0 & 0 \\
\hline 216 & squirrel & 84 & 81 & 3 & 0 & 0 & 94 & 85 & 4,1 & 1 & $3(1)$ \\
\hline 217 & star & 84 & 47 & 37 & 0 & 0 & 94 & 64 & $25,3,2$ & 0 & 0 \\
\hline 218 & stool & 84 & 55 & $19,5,1$ & 0 & $2,1,1$ & 94 & 34 & $27,10,5,4,2,1,1$ & 2 & $4,2,2$ \\
\hline 219 & stove & 84 & 0 & 0 & 70 & $5,2,7(1)$ & 94 & 0 & 0 & 81 & $4,3,2,4(1)$ \\
\hline 220 & strawberry & 84 & 82 & 0 & 0 & 1,1 & 94 & 93 & 0 & 1 & 0 \\
\hline 221 & suitcase & 87 & 35 & $17,3,2,3(1)$ & 8 & $5,5,2,2,5(1)$ & 89 & 15 & 14,1 & 24 & $11,10,7,2,2,3(1)$ \\
\hline 222 & sun & 84 & 0 & 0 & 0 & $78,3,2,1$ & 94 & 1 & 0 & 1 & $62,10,6,6,2,7(1)$ \\
\hline 223 & swan & 84 & 82 & 0 & 0 & 2 & 94 & 88 & 0 & 0 & 5,1 \\
\hline 224 & sweater & 87 & 49 & $9,3,4(1)$ & 0 & $17,2,2,1$ & 89 & 54 & 19,2 & 0 & $12,1,1$ \\
\hline 225 & swing & 84 & 0 & 0 & 50 & $7,3(4), 2,2,11(1)$ & 94 & 0 & 0 & 44 & $9,8,4,3,3(2), 20(1)$ \\
\hline 226 & table & 87 & 67 & 8 & 0 & $2,2,8(1)$ & 89 & 83 & 1 & 1 & $2,1,1$ \\
\hline 227 & telephone & 84 & 18 & 0 & 42 & $13,3,2,2,4(1)$ & 94 & 19 & 1 & 59 & $4,2,2,7(1)$ \\
\hline 228 & television & 84 & 2 & 9 & 42 & $13,4,4(2), 6(1)$ & 94 & 1 & $14,2,1$ & 57 & $5,2,2,10(1)$ \\
\hline 229 & tennis racket & 87 & 28 & 7 & 3 & $32,4,3,2,2,6(1)$ & 89 & 15 & $2,2,1$ & 3 & $52,3,3(2), 5(1)$ \\
\hline 230 & thimble & 87 & 34 & $4,2,2,1,1$ & 20 & $7,2,2,12(1)$ & 89 & 20 & 1 & 32 & $17,5,3,3,8(1)$ \\
\hline 231 & thumb & 87 & 27 & 12 & 29 & $5,3,3,2,2,4(1)$ & 89 & 20 & 6 & 36 & $6,4,3,4(2), 6(1)$ \\
\hline 232 & tie & 84 & 45 & 8 & 9 & $10,5,3,4(1)$ & 94 & 37 & 10 & 8 & $17,8,2,2,10(1)$ \\
\hline 233 & tiger & 84 & 20 & 0 & 0 & $36,20,3,2,2,1$ & 94 & 26 & $2,1,1$ & 0 & $33,20,4,4,3(1)$ \\
\hline
\end{tabular}


Table 1 (continued)

\begin{tabular}{|c|c|c|c|c|c|c|c|c|c|c|c|}
\hline \multirow[t]{2}{*}{ No } & \multirow[t]{2}{*}{ Name } & \multicolumn{5}{|c|}{ Silhouettes } & \multicolumn{5}{|c|}{ Outlines } \\
\hline & & $n$ & exact & other correct & blank & other incorrect & $n$ & exact & other correct & blank & other incorrect \\
\hline 234 & toaster & 87 & 7 & 0 & 36 & $11,6,5,5,3,3(2), 8(1)$ & 89 & 10 & 0 & 51 & $7,4,4,3,3,7(1)$ \\
\hline 235 & toe & 87 & 0 & 0 & 58 & $8,5,3,3,2,8(1)$ & 89 & 0 & 0 & 73 & $5(2), 6(1)$ \\
\hline 236 & tomato & 84 & 57 & 0 & 5 & $9,7,3,3(1)$ & 94 & 44 & 0 & 15 & $17,8,3(2), 4(1)$ \\
\hline 237 & toothbrush & 84 & 83 & 0 & 1 & 0 & 94 & 90 & 0 & 1 & $3(1)$ \\
\hline 238 & top & 87 & 4 & 2 & 16 & $25,10,7,4,3,3,2,2,9(1)$ & 89 & 6 & 0 & 18 & $35,7,3,4(2), 12(1)$ \\
\hline 239 & traffic light & 87 & 10 & 1 & 45 & $6,3(3), 3(2), 10(1)$ & 89 & 4 & 0 & 38 & $10,9,6,5,4,2,11(1)$ \\
\hline 240 & train & 87 & 1 & 0 & 58 & $4,3(2), 18(1)$ & 89 & 1 & 0 & 63 & $5,2,2,16(1)$ \\
\hline 241 & tree & 87 & 87 & 0 & 0 & 0 & 89 & 88 & 1 & 0 & 0 \\
\hline 242 & truck & 87 & 81 & $3,2,1$ & 0 & 0 & 89 & 85 & 4 & 0 & 0 \\
\hline 243 & trumpet & 87 & 86 & 1 & 0 & 0 & 89 & 88 & 0 & 0 & 1 \\
\hline 244 & turtle & 87 & 87 & 0 & 0 & 0 & 89 & 88 & 0 & 1 & 0 \\
\hline 245 & umbrella & 87 & 87 & 0 & 0 & 0 & 89 & 87 & 2 & 0 & 0 \\
\hline 246 & vase & 84 & 83 & 1 & 0 & 0 & 94 & 89 & 1 & 3 & 1 \\
\hline 247 & vest & 84 & 2 & $16,7,5,3(2), 1$ & 25 & $5,3,4(2), 6(1)$ & 94 & 2 & $15,7,2,6(1)$ & 48 & $5,2,7(1)$ \\
\hline 248 & violin & 87 & 70 & 1,1 & 0 & $9,4,1,1$ & 89 & 66 & 0 & 0 & 17,6 \\
\hline 249 & wagon & 84 & 10 & $14,13,10,8,6,4,4,3,2,(3) 1$ & 2 & $2,3(1)$ & 94 & 1 & $9,8,7,7,6,6,2,2,13(1)$ & 24 & $2,2,5(1)$ \\
\hline 250 & watch & 87 & 56 & $8,8,1$ & 0 & $9,2,2,1$ & 89 & 48 & 15,1 & 0 & $5,5,2,2,1,1$ \\
\hline 251 & watering can & 87 & 86 & 0 & 0 & 1 & 89 & 85 & 1,1 & 0 & 1,1 \\
\hline 252 & watermelon & 87 & 4 & 2,1 & 23 & $21,14,5,3,14(1)$ & 89 & 0 & 6,1 & 17 & $25,23,4,3,3,2,5(1)$ \\
\hline 253 & well & 84 & 0 & 0 & 47 & $9,7,4,4(2), 9(1)$ & 94 & 1 & 0 & 62 & $6,4,3,2,16(1)$ \\
\hline 254 & wheel & 87 & 0 & 1 & 3 & $53,12,6,3,2,2,5(1)$ & 89 & 0 & 0 & 1 & $51,21,4,3,2,2,5(1)$ \\
\hline 255 & whistle & 84 & 13 & 1 & 55 & $6,2,2,5(1)$ & 94 & 21 & 1,1 & 64 & $7(1)$ \\
\hline 256 & windmill & 84 & 33 & 47 & 4 & 0 & 94 & 57 & 36,1 & 0 & 0 \\
\hline 257 & window & 84 & 0 & 0 & 62 & $8,2,2,10(1)$ & 94 & 0 & 0 & 75 & $3,3,2,2,9(1)$ \\
\hline 258 & wineglass & 87 & 30 & $51,2,3(1)$ & 0 & 1 & 89 & 39 & 47,3 & 0 & 0 \\
\hline 259 & wrench & 87 & 12 & $29,6,4,4,2,4(1)$ & 3 & $18,2,3(1)$ & 89 & 16 & $16,10,10,4,2,1,1$ & 1 & $25,3(1)$ \\
\hline 260 & zebra & 87 & 1 & 1 & 0 & $82,3(1)$ & 89 & 0 & 0 & 0 & $80,6,2,1$ \\
\hline
\end{tabular}




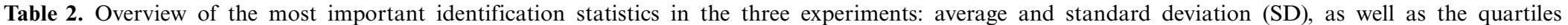

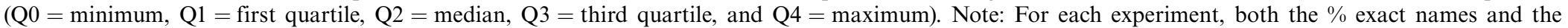
$\%$ correct concepts are given.

\begin{tabular}{|c|c|c|c|c|c|c|c|c|c|}
\hline \multirow[t]{2}{*}{ No } & \multirow[t]{2}{*}{ Name } & \multicolumn{2}{|c|}{ Silhouettes } & \multicolumn{2}{|l|}{ Outlines } & \multicolumn{2}{|c|}{ Inverted silhouettes } & \multicolumn{2}{|c|}{ New silhouettes } \\
\hline & & $\begin{array}{l}\text { \% exact } \\
\text { name }\end{array}$ & $\begin{array}{l}\% \text { correct } \\
\text { concept }\end{array}$ & $\begin{array}{l}\text { \% exact } \\
\text { name }\end{array}$ & $\begin{array}{l}\text { \% correct } \\
\text { concept }\end{array}$ & $\begin{array}{l}\text { \% exact } \\
\text { name }\end{array}$ & $\begin{array}{l}\text { \% correct } \\
\text { concept }\end{array}$ & $\begin{array}{l}\text { \% exact } \\
\text { name }\end{array}$ & $\begin{array}{l}\% \text { correct } \\
\text { concept }\end{array}$ \\
\hline 1 & accordion & 0.00 & 0.00 & 0.00 & 0.00 & & & & \\
\hline 2 & airplane & 100.00 & 100.00 & 96.63 & 97.75 & 99.14 & 100.00 & & \\
\hline 3 & alligator & 91.67 & 92.86 & 82.98 & 88.30 & 91.53 & 92.37 & & \\
\hline 4 & anchor & 100.00 & 100.00 & 95.51 & 95.51 & 94.83 & 95.69 & 100.00 & 100.00 \\
\hline 5 & ant & 79.31 & 87.36 & 58.43 & 68.54 & 77.97 & 91.53 & 95.18 & 95.18 \\
\hline 6 & apple & 98.85 & 98.85 & 98.88 & 98.88 & 97.41 & 97.41 & & \\
\hline 7 & arm & 95.40 & 100.00 & 97.75 & 97.75 & 78.45 & 99.14 & & \\
\hline 8 & arrow & 48.28 & 48.28 & 59.55 & 59.55 & 76.27 & 100.00 & & \\
\hline 9 & artichoke & 4.60 & 5.75 & 0.00 & 0.00 & 19.83 & 20.69 & & \\
\hline 10 & ashtray & 0.00 & 0.00 & 0.00 & 0.00 & & & & \\
\hline 11 & asparagus & 1.15 & 1.15 & 2.25 & 2.25 & 13.56 & 13.56 & & \\
\hline 12 & axe & 87.36 & 93.10 & 91.01 & 96.63 & 88.14 & 93.22 & & \\
\hline 13 & baby carriage & 64.37 & 98.85 & 78.65 & 98.88 & 67.24 & 100.00 & 53.01 & 98.80 \\
\hline 14 & ball & 59.77 & 62.07 & 53.93 & 53.93 & 40.68 & 46.61 & & \\
\hline 15 & balloon & 98.85 & 100.00 & 96.63 & 96.63 & 97.46 & 100.00 & & \\
\hline 16 & banana & 97.70 & 97.70 & 96.63 & 96.63 & 82.76 & 82.76 & & \\
\hline 17 & barn & 1.19 & 4.76 & 0.00 & 4.26 & 1.72 & 56.90 & & \\
\hline 18 & barrel & 63.22 & 75.86 & 32.58 & 33.71 & 58.47 & 77.12 & & \\
\hline 19 & baseball bat & 17.86 & 82.14 & 25.53 & 82.98 & 19.49 & 92.37 & & \\
\hline 20 & basket & 0.00 & 6.90 & 8.99 & 8.99 & 3.39 & 8.47 & 38.55 & 92.77 \\
\hline 21 & bear & 85.06 & 98.85 & 74.16 & 97.75 & 73.28 & 99.14 & & \\
\hline 22 & bed & 98.81 & 100.00 & 96.81 & 100.00 & 100.00 & 100.00 & & \\
\hline 23 & bee & 4.60 & 34.48 & 4.49 & 39.33 & 11.86 & 47.46 & & \\
\hline 24 & beetle & 79.31 & 93.10 & 59.55 & 75.28 & 58.47 & 87.29 & 74.70 & 93.98 \\
\hline 25 & bell & 51.72 & 89.66 & 62.92 & 98.88 & 43.97 & 93.97 & 59.04 & 100.00 \\
\hline 26 & belt & 0.00 & 0.00 & 0.00 & 0.00 & & & 46.99 & 78.31 \\
\hline 27 & bicycle & 93.10 & 96.55 & 76.40 & 76.40 & 70.34 & 82.20 & 97.59 & 100.00 \\
\hline 28 & bird & 91.95 & 98.85 & 92.13 & 100.00 & 29.31 & 100.00 & 34.94 & 100.00 \\
\hline 29 & blouse & 4.60 & 6.90 & 6.74 & 12.36 & 7.63 & 16.95 & & \\
\hline 30 & book & 13.10 & 13.10 & 1.06 & 1.06 & 92.24 & 93.10 & & \\
\hline 31 & boot & 91.67 & 100.00 & 92.55 & 98.94 & 84.75 & 97.46 & & \\
\hline
\end{tabular}


Table 2 (continued)

\begin{tabular}{|c|c|c|c|c|c|c|c|c|c|}
\hline \multirow[t]{2}{*}{ No } & \multirow[t]{2}{*}{ Name } & \multicolumn{2}{|c|}{ Silhouettes } & \multicolumn{2}{|l|}{ Outlines } & \multicolumn{2}{|c|}{ Inverted silhouettes } & \multicolumn{2}{|c|}{ New silhouettes } \\
\hline & & $\begin{array}{l}\% \text { exact } \\
\text { name }\end{array}$ & $\begin{array}{l}\% \text { correct } \\
\text { concept }\end{array}$ & $\begin{array}{l}\% \text { exact } \\
\text { name }\end{array}$ & $\begin{array}{l}\% \text { correct } \\
\text { concept }\end{array}$ & $\begin{array}{l}\% \text { exact } \\
\text { name }\end{array}$ & $\begin{array}{l}\% \text { correct } \\
\text { concept }\end{array}$ & $\begin{array}{l}\text { \% exact } \\
\text { name }\end{array}$ & $\begin{array}{l}\% \text { correct } \\
\text { concept }\end{array}$ \\
\hline 32 & bottle & 86.21 & 100.00 & 94.38 & 100.00 & 88.98 & 100.00 & & \\
\hline 33 & bow & 97.62 & 100.00 & 90.43 & 95.74 & 89.83 & 100.00 & & \\
\hline 34 & bowl & 74.71 & 86.21 & 86.52 & 89.89 & 72.88 & 91.53 & & \\
\hline 35 & box & 3.45 & 10.34 & 0.00 & 0.00 & 27.59 & 36.21 & & \\
\hline 36 & bread & 41.67 & 41.67 & 42.55 & 43.62 & 70.34 & 94.92 & & \\
\hline 37 & broom & 26.19 & 38.10 & 11.70 & 15.96 & 80.17 & 96.55 & & \\
\hline 38 & brush & 61.90 & 84.52 & 27.66 & 53.19 & 50.85 & 100.00 & & \\
\hline 39 & bus & 34.48 & 51.72 & 39.33 & 61.80 & 42.37 & 68.64 & & \\
\hline 40 & butterfly & 100.00 & 100.00 & 100.00 & 100.00 & & & & \\
\hline 41 & button & 0.00 & 0.00 & 0.00 & 0.00 & & & 91.57 & 91.57 \\
\hline 42 & cake & 0.00 & 0.00 & 0.00 & 0.00 & & & & \\
\hline 43 & camel & 71.43 & 98.81 & 65.96 & 97.87 & 77.97 & 100.00 & & \\
\hline 44 & candle & 98.81 & 98.81 & 92.55 & 93.62 & 90.68 & 100.00 & & \\
\hline 45 & cannon & 4.60 & 4.60 & 15.73 & 15.73 & 23.28 & 23.28 & 95.18 & 97.59 \\
\hline 46 & cap & 8.33 & 9.52 & 3.19 & 3.19 & 27.59 & 28.45 & & \\
\hline 47 & car & 97.62 & 100.00 & 100.00 & 100.00 & 88.14 & 100.00 & & \\
\hline 48 & carrot & 97.70 & 97.70 & 100.00 & 100.00 & 98.31 & 100.00 & & \\
\hline 49 & cat & 72.62 & 100.00 & 57.45 & 100.00 & 63.79 & 100.00 & & \\
\hline 50 & caterpillar & 59.77 & 77.01 & 61.80 & 73.03 & 76.72 & 92.24 & & \\
\hline 51 & celery & 51.19 & 57.14 & 43.62 & 48.94 & 64.41 & 73.73 & & \\
\hline 52 & chain & 8.33 & 21.43 & 6.38 & 12.77 & 12.71 & 28.81 & 92.77 & 98.80 \\
\hline 53 & chair & 95.24 & 100.00 & 94.68 & 100.00 & 99.14 & 100.00 & 100.00 & 100.00 \\
\hline 54 & cherry & 95.24 & 98.81 & 88.30 & 95.74 & 88.98 & 95.76 & & \\
\hline 55 & chicken & 96.55 & 98.85 & 97.75 & 100.00 & 97.41 & 98.28 & & \\
\hline 56 & chisel & 14.94 & 16.09 & 4.49 & 4.49 & 24.14 & 27.59 & & \\
\hline 57 & church & 92.86 & 94.05 & 95.74 & 98.94 & 88.98 & 100.00 & & \\
\hline 58 & cigar & 4.76 & 4.76 & 2.13 & 2.13 & 0.00 & 0.00 & & \\
\hline 59 & cigarette & 72.62 & 77.38 & 67.02 & 72.34 & 79.31 & 93.97 & & \\
\hline 60 & clock & 1.15 & 1.15 & 2.25 & 2.25 & 8.62 & 8.62 & & \\
\hline 61 & clothespin & 71.43 & 85.71 & 62.77 & 78.72 & 61.86 & 97.46 & 51.81 & 100.00 \\
\hline 62 & cloud & 2.30 & 2.30 & 2.25 & 2.25 & 11.86 & 12.71 & & \\
\hline 63 & clown & 0.00 & 0.00 & 1.06 & 1.06 & 3.39 & 3.39 & & \\
\hline
\end{tabular}


Table 2 (continued)

\begin{tabular}{|c|c|c|c|c|c|c|c|c|c|}
\hline \multirow[t]{2}{*}{ No } & \multirow[t]{2}{*}{ Name } & \multicolumn{2}{|c|}{ Silhouettes } & \multicolumn{2}{|l|}{ Outlines } & \multicolumn{2}{|c|}{ Inverted silhouettes } & \multicolumn{2}{|c|}{ New silhouettes } \\
\hline & & $\begin{array}{l}\text { \% exact } \\
\text { name }\end{array}$ & $\begin{array}{l}\text { \% correct } \\
\text { concept }\end{array}$ & $\begin{array}{l}\overline{\%} \text { exact } \\
\text { name }\end{array}$ & $\begin{array}{l}\% \text { correct } \\
\text { concept }\end{array}$ & $\begin{array}{l}\text { \% exact } \\
\text { name }\end{array}$ & $\begin{array}{l}\% \text { correct } \\
\text { concept }\end{array}$ & $\begin{array}{l}\% \text { exact } \\
\text { name }\end{array}$ & $\begin{array}{l}\text { \% correct } \\
\text { concept }\end{array}$ \\
\hline 64 & coat & 67.86 & 84.52 & 65.96 & 87.23 & 36.44 & 89.83 & & \\
\hline 65 & comb & 100.00 & 100.00 & 97.87 & 100.00 & 96.61 & 100.00 & & \\
\hline 66 & corn & 2.30 & 6.90 & 6.74 & 6.74 & 16.10 & 31.36 & & \\
\hline 67 & couch & 65.48 & 98.81 & 68.09 & 96.81 & 53.45 & 99.14 & & \\
\hline 68 & cow & 85.71 & 100.00 & 87.23 & 97.87 & 94.83 & 98.28 & & \\
\hline 69 & crown & 68.97 & 68.97 & 53.93 & 53.93 & 16.10 & 16.10 & & \\
\hline 70 & cup & 33.33 & 89.29 & 38.30 & 81.91 & 39.83 & 96.61 & 43.37 & 100.00 \\
\hline 71 & deer & 94.25 & 100.00 & 96.63 & 100.00 & 85.34 & 100.00 & & \\
\hline 72 & desk & 24.14 & 26.44 & 1.12 & 1.12 & 93.10 & 99.14 & & \\
\hline 73 & $\operatorname{dog}$ & 100.00 & 100.00 & 100.00 & 100.00 & & & & \\
\hline 74 & doll & 70.11 & 78.16 & 68.54 & 68.54 & 78.45 & 82.76 & & \\
\hline 75 & donkey & 98.81 & 100.00 & 91.49 & 91.49 & 94.92 & 95.76 & & \\
\hline 76 & door & 5.75 & 8.05 & 7.87 & 7.87 & 68.64 & 74.58 & & \\
\hline 77 & doorknob & 14.29 & 14.29 & 24.47 & 27.66 & 23.73 & 27.97 & & \\
\hline 78 & dress & 52.87 & 100.00 & 59.55 & 97.75 & 38.79 & 100.00 & & \\
\hline 79 & dresser & 79.76 & 88.10 & 54.26 & 62.77 & 67.24 & 93.10 & & \\
\hline 80 & drum & 8.05 & 8.05 & 2.25 & 2.25 & 52.54 & 55.08 & & \\
\hline 81 & duck & 98.81 & 98.81 & 96.81 & 97.87 & 100.00 & 100.00 & 100.00 & 100.00 \\
\hline 82 & eagle & 35.71 & 46.43 & 32.98 & 45.74 & 45.69 & 56.03 & & \\
\hline 83 & ear & 8.33 & 8.33 & 1.06 & 1.06 & 76.72 & 77.59 & & \\
\hline 84 & elephant & 100.00 & 100.00 & 100.00 & 100.00 & & & & \\
\hline 85 & envelope & 0.00 & 0.00 & 0.00 & 0.00 & & & & \\
\hline 86 & eye & 1.15 & 1.15 & 0.00 & 0.00 & 3.39 & 3.39 & & \\
\hline 87 & fence & 90.48 & 96.43 & 60.64 & 76.60 & 77.59 & 97.41 & 81.93 & 97.59 \\
\hline 88 & finger & 45.24 & 78.57 & 19.15 & 51.06 & 15.52 & 91.38 & & \\
\hline 89 & fish & 96.43 & 98.81 & 100.00 & 100.00 & 96.55 & 99.14 & & \\
\hline 90 & flag & 96.55 & 100.00 & 98.88 & 98.88 & 90.52 & 99.14 & 83.13 & 100.00 \\
\hline 91 & flower & 97.62 & 100.00 & 98.94 & 100.00 & 86.44 & 96.61 & & \\
\hline 92 & flute & 16.09 & 24.14 & 13.48 & 13.48 & 0.00 & 6.03 & & \\
\hline 93 & fly & 86.90 & 98.81 & 82.98 & 94.68 & 94.83 & 97.41 & & \\
\hline 94 & foot & 98.81 & 98.81 & 85.11 & 89.36 & 98.31 & 99.15 & & \\
\hline 95 & football & 44.05 & 47.62 & 17.02 & 17.02 & 30.17 & 33.62 & & \\
\hline
\end{tabular}


Table 2 (continued)

\begin{tabular}{|c|c|c|c|c|c|c|c|c|c|}
\hline \multirow[t]{2}{*}{ No } & \multirow[t]{2}{*}{ Name } & \multicolumn{2}{|c|}{ Silhouettes } & \multicolumn{2}{|l|}{ Outlines } & \multicolumn{2}{|c|}{ Inverted silhouettes } & \multicolumn{2}{|c|}{ New silhouettes } \\
\hline & & $\begin{array}{l}\% \text { exact } \\
\text { name }\end{array}$ & $\begin{array}{l}\% \text { correct } \\
\text { concept }\end{array}$ & $\begin{array}{l}\text { \% exact } \\
\text { name }\end{array}$ & $\begin{array}{l}\text { \% correct } \\
\text { concept }\end{array}$ & $\begin{array}{l}\text { \% exact } \\
\text { name }\end{array}$ & $\begin{array}{l}\% \text { correct } \\
\text { concept }\end{array}$ & $\begin{array}{l}\text { \% exact } \\
\text { name }\end{array}$ & $\begin{array}{l}\text { \% correct } \\
\text { concept }\end{array}$ \\
\hline 96 & football helmet & 70.24 & 80.95 & 62.77 & 69.15 & 68.10 & 88.79 & 50.60 & 75.90 \\
\hline 97 & fork & 100.00 & 100.00 & 100.00 & 100.00 & & & & \\
\hline 98 & fox & 89.66 & 90.80 & 91.01 & 91.01 & 72.03 & 72.03 & & \\
\hline 99 & French horn & 51.72 & 88.51 & 43.82 & 88.76 & 47.46 & 86.44 & 46.99 & 85.54 \\
\hline 100 & frog & 98.85 & 100.00 & 93.26 & 100.00 & 84.48 & 99.14 & & \\
\hline 101 & frying pan & 1.15 & 88.51 & 2.25 & 75.28 & 17.80 & 94.07 & 3.61 & 98.80 \\
\hline 102 & garbage can & 48.28 & 79.31 & 28.09 & 66.29 & 59.48 & 98.28 & & \\
\hline 103 & giraffe & 100.00 & 100.00 & 100.00 & 100.00 & & & & \\
\hline 104 & glass & 48.28 & 64.37 & 85.39 & 88.76 & 55.93 & 100.00 & & \\
\hline 105 & glasses & 86.21 & 100.00 & 98.88 & 100.00 & 98.28 & 100.00 & & \\
\hline 106 & glove & 76.19 & 76.19 & 62.77 & 64.89 & 94.92 & 94.92 & & \\
\hline 107 & goat & 80.95 & 91.67 & 69.15 & 86.17 & 75.42 & 100.00 & & \\
\hline 108 & gorilla & 47.13 & 97.70 & 61.80 & 92.13 & 16.38 & 92.24 & & \\
\hline 109 & grapes & 27.38 & 40.48 & 20.21 & 47.87 & 64.66 & 93.97 & & \\
\hline 110 & grasshopper & 22.99 & 51.72 & 12.36 & 39.33 & 46.61 & 55.93 & & \\
\hline 111 & guitar & 100.00 & 100.00 & 100.00 & 100.00 & & & & \\
\hline 112 & gun & 47.62 & 84.52 & 39.36 & 78.72 & 35.34 & 79.31 & & \\
\hline 113 & hair & 0.00 & 0.00 & 0.00 & 0.00 & & & & \\
\hline 114 & hammer & 95.40 & 98.85 & 97.75 & 98.88 & 93.22 & 95.76 & & \\
\hline 115 & hand & 88.51 & 90.80 & 70.79 & 70.79 & 74.58 & 77.12 & & \\
\hline 116 & hanger & 22.99 & 100.00 & 22.47 & 100.00 & 25.42 & 100.00 & 34.94 & 100.00 \\
\hline 117 & harp & 84.52 & 85.71 & 74.47 & 74.47 & 91.38 & 92.24 & & \\
\hline 118 & hat & 100.00 & 100.00 & 98.94 & 98.94 & 99.14 & 100.00 & & \\
\hline 119 & heart & 90.80 & 100.00 & 100.00 & 100.00 & 75.86 & 100.00 & & \\
\hline 120 & helicopter & 100.00 & 100.00 & 98.94 & 98.94 & 99.15 & 100.00 & & \\
\hline 121 & horse & 98.81 & 100.00 & 100.00 & 100.00 & 100.00 & 100.00 & & \\
\hline 122 & house & 10.34 & 12.64 & 26.97 & 26.97 & 92.37 & 95.76 & & \\
\hline 123 & iron & 24.14 & 24.14 & 52.81 & 52.81 & 88.14 & 90.68 & 100.00 & 100.00 \\
\hline 124 & iron board & 3.57 & 3.57 & 76.60 & 77.66 & 86.21 & 93.10 & 89.16 & 97.59 \\
\hline 125 & jacket & 4.60 & 83.91 & 11.24 & 85.39 & 16.10 & 92.37 & & \\
\hline 126 & kangaroo & 97.62 & 98.81 & 100.00 & 100.00 & 100.00 & 100.00 & & \\
\hline 127 & kettle & 14.29 & 61.90 & 18.09 & 63.83 & 27.59 & 81.90 & 26.51 & 92.77 \\
\hline
\end{tabular}


Table 2 (continued)

\begin{tabular}{|c|c|c|c|c|c|c|c|c|c|}
\hline \multirow[t]{2}{*}{ No } & \multirow[t]{2}{*}{ Name } & \multicolumn{2}{|c|}{ Silhouettes } & \multicolumn{2}{|l|}{ Outlines } & \multicolumn{2}{|c|}{ Inverted silhouettes } & \multicolumn{2}{|c|}{ New silhouettes } \\
\hline & & $\begin{array}{l}\text { \% exact } \\
\text { name }\end{array}$ & $\begin{array}{l}\text { \% correct } \\
\text { concept }\end{array}$ & $\begin{array}{l}\text { \% exact } \\
\text { name }\end{array}$ & $\begin{array}{l}\% \text { correct } \\
\text { concept }\end{array}$ & $\begin{array}{l}\text { \% exact } \\
\text { name }\end{array}$ & $\begin{array}{l}\% \text { correct } \\
\text { concept }\end{array}$ & $\begin{array}{l}\text { \% exact } \\
\text { name }\end{array}$ & $\begin{array}{l}\text { \% correct } \\
\text { concept }\end{array}$ \\
\hline 128 & key & 98.85 & 100.00 & 98.88 & 98.88 & 86.21 & 87.93 & 98.80 & 100.00 \\
\hline 129 & kite & 82.76 & 97.70 & 97.75 & 100.00 & 80.17 & 99.14 & & \\
\hline 130 & knife & 56.32 & 57.47 & 76.40 & 76.40 & 87.93 & 89.66 & & \\
\hline 131 & ladder & 1.19 & 1.19 & 4.26 & 4.26 & 18.64 & 19.49 & 93.98 & 98.80 \\
\hline 132 & lamp & 77.38 & 100.00 & 68.09 & 100.00 & 64.66 & 100.00 & & \\
\hline 133 & leaf & 73.81 & 100.00 & 74.47 & 100.00 & 63.56 & 100.00 & & \\
\hline 134 & leg & 95.24 & 100.00 & 96.81 & 100.00 & 89.83 & 100.00 & & \\
\hline 135 & lemon & 93.10 & 93.10 & 93.26 & 93.26 & 94.07 & 94.92 & & \\
\hline 136 & leopard & 3.57 & 39.29 & 6.38 & 34.04 & 12.07 & 57.76 & & \\
\hline 137 & lettuce & 4.60 & 8.05 & 8.99 & 10.11 & 10.34 & 36.21 & & \\
\hline 138 & light bulb & 22.62 & 83.33 & 27.66 & 87.23 & 33.05 & 97.46 & & \\
\hline 139 & light switch & 0.00 & 0.00 & 0.00 & 0.00 & & & & \\
\hline 140 & lion & 97.62 & 97.62 & 100.00 & 100.00 & 100.00 & 100.00 & & \\
\hline 141 & lips & 54.02 & 98.85 & 56.18 & 98.88 & 44.07 & 96.61 & & \\
\hline 142 & lobster & 90.80 & 90.80 & 91.01 & 92.13 & 85.34 & 86.21 & & \\
\hline 143 & lock & 57.47 & 97.70 & 53.93 & 97.75 & 48.31 & 99.15 & & \\
\hline 144 & mitten & 58.33 & 100.00 & 50.00 & 100.00 & 56.78 & 100.00 & & \\
\hline 145 & monkey & 71.26 & 100.00 & 94.38 & 100.00 & 88.98 & 100.00 & & \\
\hline 146 & moon & 81.61 & 100.00 & 91.01 & 100.00 & 93.97 & 100.00 & & \\
\hline 147 & motorcycle & 22.99 & 100.00 & 28.09 & 100.00 & 39.83 & 99.15 & 13.25 & 100.00 \\
\hline 148 & mountain & 30.95 & 60.71 & 20.21 & 58.51 & 55.08 & 92.37 & & \\
\hline 149 & mouse & 82.14 & 82.14 & 82.98 & 91.49 & 53.39 & 55.93 & & \\
\hline 150 & mushroom & 97.62 & 100.00 & 98.94 & 98.94 & 92.37 & 97.46 & & \\
\hline 151 & nail & 28.74 & 72.41 & 14.61 & 57.30 & 24.14 & 94.83 & & \\
\hline 152 & nail file & 0.00 & 1.19 & 1.06 & 3.19 & 3.45 & 12.07 & & \\
\hline 153 & necklace & 0.00 & 0.00 & 0.00 & 0.00 & & & 44.58 & 97.59 \\
\hline 154 & needle & 48.81 & 57.14 & 56.38 & 60.64 & 80.51 & 83.05 & & \\
\hline 155 & nose & 3.45 & 3.45 & 2.25 & 2.25 & 41.38 & 41.38 & & \\
\hline 156 & nut & 0.00 & 0.00 & 0.00 & 0.00 & & & & \\
\hline 157 & onion & 41.67 & 89.29 & 52.13 & 82.98 & 49.14 & 96.55 & & \\
\hline 158 & orange & 14.29 & 23.81 & 14.89 & 27.66 & 18.97 & 31.90 & & \\
\hline
\end{tabular}


Table 2 (continued)

\begin{tabular}{|c|c|c|c|c|c|c|c|c|c|}
\hline \multirow[t]{2}{*}{ No } & \multirow[t]{2}{*}{ Name } & \multicolumn{2}{|c|}{ Silhouettes } & \multicolumn{2}{|l|}{ Outlines } & \multicolumn{2}{|c|}{ Inverted silhouettes } & \multicolumn{2}{|c|}{ New silhouettes } \\
\hline & & $\begin{array}{l}\% \text { exact } \\
\text { name }\end{array}$ & $\begin{array}{l}\% \text { correct } \\
\text { concept }\end{array}$ & $\begin{array}{l}\% \text { exact } \\
\text { name }\end{array}$ & $\begin{array}{l}\% \text { correct } \\
\text { concept }\end{array}$ & $\begin{array}{l}\% \text { exact } \\
\text { name }\end{array}$ & $\begin{array}{l}\% \text { correct } \\
\text { concept }\end{array}$ & $\begin{array}{l}\% \text { exact } \\
\text { name }\end{array}$ & $\begin{array}{l}\% \text { correct } \\
\text { concept }\end{array}$ \\
\hline 159 & ostrich & 91.95 & 91.95 & 91.01 & 91.01 & 94.07 & 98.31 & & \\
\hline 160 & owl & 76.19 & 76.19 & 68.09 & 68.09 & 97.41 & 97.41 & & \\
\hline 161 & paintbrush & 90.80 & 95.40 & 77.53 & 77.53 & 94.83 & 99.14 & & \\
\hline 162 & pants & 97.70 & 100.00 & 100.00 & 100.00 & 95.76 & 100.00 & & \\
\hline 163 & peach & 0.00 & 0.00 & 1.12 & 1.12 & 4.31 & 4.31 & & \\
\hline 164 & peacock & 93.10 & 93.10 & 98.88 & 98.88 & 98.31 & 98.31 & & \\
\hline 165 & peanut & 27.38 & 72.62 & 11.70 & 51.06 & 38.98 & 82.20 & & \\
\hline 166 & pear & 100.00 & 100.00 & 100.00 & 100.00 & & & & \\
\hline 167 & pen & 42.86 & 98.81 & 46.81 & 88.30 & 0.86 & 1.72 & & \\
\hline 168 & pencil & 16.67 & 17.86 & 19.15 & 20.21 & 99.15 & 99.15 & & \\
\hline 169 & penguin & 98.85 & 98.85 & 98.88 & 98.88 & 91.38 & 92.24 & & \\
\hline 170 & pepper & 4.76 & 4.76 & 7.45 & 7.45 & 5.08 & 5.08 & & \\
\hline 171 & piano & 53.57 & 98.81 & 55.32 & 94.68 & 28.45 & 100.00 & & \\
\hline 172 & pig & 88.51 & 98.85 & 85.39 & 92.13 & 86.21 & 98.28 & & \\
\hline 173 & pineapple & 98.85 & 98.85 & 97.75 & 97.75 & 100.00 & 100.00 & & \\
\hline 174 & pipe & 98.81 & 98.81 & 100.00 & 100.00 & 99.14 & 100.00 & & \\
\hline 175 & pitcher & 41.38 & 73.56 & 47.19 & 65.17 & 44.83 & 91.38 & 69.88 & 100.00 \\
\hline 176 & pliers & 63.22 & 97.70 & 60.67 & 100.00 & 53.39 & 94.07 & 66.27 & 97.59 \\
\hline 177 & plug & 88.51 & 93.10 & 73.03 & 75.28 & 91.38 & 93.10 & & \\
\hline 178 & pocketbook & 0.00 & 0.00 & 0.00 & 2.25 & 0.86 & 1.72 & 95.18 & 97.59 \\
\hline 179 & pot & 15.48 & 91.67 & 9.57 & 67.02 & 27.12 & 94.07 & & \\
\hline 180 & potato & 10.34 & 10.34 & 13.48 & 13.48 & 27.59 & 31.90 & & \\
\hline 181 & pumpkin & 2.38 & 2.38 & 1.06 & 1.06 & 10.17 & 10.17 & & \\
\hline 182 & rabbit & 96.55 & 98.85 & 98.88 & 98.88 & 97.46 & 100.00 & & \\
\hline 183 & raccoon & 26.44 & 36.78 & 7.87 & 7.87 & 4.31 & 6.03 & & \\
\hline 184 & record player & 0.00 & 0.00 & 0.00 & 0.00 & & & & \\
\hline 185 & refrigerator & 1.19 & 1.19 & 1.06 & 3.19 & 5.17 & 20.69 & & \\
\hline 186 & rhinoceros & 97.62 & 98.81 & 92.55 & 93.62 & 94.83 & 95.69 & & \\
\hline 187 & ring & 0.00 & 0.00 & 1.06 & 2.13 & 1.69 & 1.69 & 89.16 & 93.98 \\
\hline 188 & rocking chair & 75.86 & 97.70 & 83.15 & 92.13 & 88.98 & 97.46 & 92.77 & 100.00 \\
\hline 189 & roller skate & 60.71 & 60.71 & 28.72 & 28.72 & 68.97 & 71.55 & & \\
\hline 190 & rolling pin & 87.36 & 96.55 & 97.75 & 97.75 & 92.24 & 99.14 & & \\
\hline
\end{tabular}


Table 2 (continued)

\begin{tabular}{|c|c|c|c|c|c|c|c|c|c|}
\hline \multirow[t]{2}{*}{ No } & \multirow[t]{2}{*}{ Name } & \multicolumn{2}{|c|}{ Silhouettes } & \multicolumn{2}{|l|}{ Outlines } & \multicolumn{2}{|c|}{ Inverted silhouettes } & \multicolumn{2}{|c|}{ New silhouettes } \\
\hline & & $\begin{array}{l}\% \text { exact } \\
\text { name }\end{array}$ & $\begin{array}{l}\% \text { correct } \\
\text { concept }\end{array}$ & $\begin{array}{l}\% \text { exact } \\
\text { name }\end{array}$ & $\begin{array}{l}\% \text { correct } \\
\text { concept }\end{array}$ & $\begin{array}{l}\% \text { exact } \\
\text { name }\end{array}$ & $\begin{array}{l}\% \text { correct } \\
\text { concept }\end{array}$ & $\begin{array}{l}\% \text { exact } \\
\text { name }\end{array}$ & $\begin{array}{l}\% \text { correct } \\
\text { concept }\end{array}$ \\
\hline 191 & rooster & 87.36 & 88.51 & 91.01 & 91.01 & 83.62 & 83.62 & & \\
\hline 192 & ruler & 1.19 & 1.19 & 3.19 & 5.32 & 16.10 & 57.63 & & \\
\hline 193 & sailboat & 52.38 & 98.81 & 75.53 & 96.81 & 66.10 & 83.90 & & \\
\hline 194 & saltshaker & 7.14 & 10.71 & 1.06 & 3.19 & 28.81 & 38.98 & & \\
\hline 195 & sandwich & 1.19 & 2.38 & 1.06 & 3.19 & 6.03 & 7.76 & & \\
\hline 196 & saw & 66.67 & 66.67 & 61.70 & 61.70 & 89.83 & 90.68 & 93.98 & 100.00 \\
\hline 197 & scissors & 100.00 & 100.00 & 98.94 & 98.94 & 100.00 & 100.00 & 98.80 & 100.00 \\
\hline 198 & screw & 42.53 & 77.01 & 43.82 & 74.16 & 47.41 & 92.24 & & \\
\hline 199 & screwdriver & 96.55 & 100.00 & 97.75 & 97.75 & 94.92 & 100.00 & & \\
\hline 200 & sea horse & 67.86 & 100.00 & 70.21 & 97.87 & 83.62 & 96.55 & & \\
\hline 201 & seal & 77.38 & 96.43 & 78.72 & 94.68 & 80.51 & 99.15 & & \\
\hline 202 & sheep & 79.31 & 81.61 & 66.29 & 67.42 & 89.83 & 90.68 & & \\
\hline 203 & shirt & 56.32 & 60.92 & 53.93 & 60.67 & 87.93 & 90.52 & & \\
\hline 204 & shoe & 100.00 & 100.00 & 100.00 & 100.00 & & & & \\
\hline 205 & skirt & 78.57 & 78.57 & 40.43 & 42.55 & 79.31 & 90.52 & & \\
\hline 206 & skunk & 8.33 & 8.33 & 9.57 & 11.70 & 7.63 & 7.63 & & \\
\hline 207 & sled & 1.19 & 1.19 & 1.06 & 1.06 & 1.69 & 1.69 & 83.13 & 98.80 \\
\hline 208 & snail & 100.00 & 100.00 & 100.00 & 100.00 & & & & \\
\hline 209 & snake & 98.81 & 98.81 & 98.94 & 98.94 & 97.46 & 100.00 & & \\
\hline 210 & snowman & 96.55 & 100.00 & 100.00 & 100.00 & 97.41 & 100.00 & & \\
\hline 211 & sock & 59.77 & 97.70 & 67.42 & 100.00 & 59.48 & 99.14 & & \\
\hline 212 & spider & 95.24 & 96.43 & 93.62 & 97.87 & 87.93 & 92.24 & 92.77 & 93.98 \\
\hline 213 & spinning wheel & 0.00 & 0.00 & 0.00 & 0.00 & & & 93.98 & 93.98 \\
\hline 214 & spool of thread & 2.30 & 22.99 & 1.12 & 11.24 & 12.07 & 62.07 & & \\
\hline 215 & spoon & 92.86 & 100.00 & 89.36 & 100.00 & 88.98 & 100.00 & & \\
\hline 216 & squirrel & 96.43 & 100.00 & 90.43 & 95.74 & 99.15 & 99.15 & & \\
\hline 217 & star & 55.95 & 100.00 & 68.09 & 100.00 & 98.31 & 100.00 & & \\
\hline 218 & stool & 65.48 & 95.24 & 36.17 & 89.36 & 39.66 & 99.14 & 40.96 & 100.00 \\
\hline 219 & stove & 0.00 & 0.00 & 0.00 & 0.00 & & & & \\
\hline 220 & strawberry & 97.62 & 97.62 & 98.94 & 98.94 & 99.15 & 99.15 & & \\
\hline 221 & suitcase & 40.23 & 68.97 & 16.85 & 33.71 & 24.14 & 61.21 & & \\
\hline 222 & sun & 0.00 & 0.00 & 1.06 & 1.06 & 10.34 & 11.21 & & \\
\hline
\end{tabular}


Table 2 (continued)

\begin{tabular}{|c|c|c|c|c|c|c|c|c|c|}
\hline \multirow[t]{2}{*}{ No } & \multirow[t]{2}{*}{ Name } & \multicolumn{2}{|c|}{ Silhouettes } & \multicolumn{2}{|l|}{ Outlines } & \multicolumn{2}{|c|}{ Inverted silhouettes } & \multicolumn{2}{|c|}{ New silhouettes } \\
\hline & & $\begin{array}{l}\% \text { exact } \\
\text { name }\end{array}$ & $\begin{array}{l}\% \text { correct } \\
\text { concept }\end{array}$ & $\begin{array}{l}\% \text { exact } \\
\text { name }\end{array}$ & $\begin{array}{l}\% \text { correct } \\
\text { concept }\end{array}$ & $\begin{array}{l}\% \text { exact } \\
\text { name }\end{array}$ & $\begin{array}{l}\% \text { correct } \\
\text { concept }\end{array}$ & $\begin{array}{l}\% \text { exact } \\
\text { name }\end{array}$ & $\begin{array}{l}\% \text { correct } \\
\text { concept }\end{array}$ \\
\hline 223 & swan & 97.62 & 97.62 & 93.62 & 93.62 & 98.31 & 98.31 & & \\
\hline 224 & sweater & 56.32 & 74.71 & 60.67 & 84.27 & 68.97 & 87.93 & & \\
\hline 225 & swing & 0.00 & 0.00 & 0.00 & 0.00 & & & 91.57 & 92.77 \\
\hline 226 & table & 77.01 & 86.21 & 93.26 & 94.38 & 97.41 & 100.00 & & \\
\hline 227 & telephone & 21.43 & 21.43 & 20.21 & 21.28 & 85.59 & 88.14 & 95.18 & 100.00 \\
\hline 228 & television & 2.38 & 13.10 & 1.06 & 19.15 & 0.00 & 0.86 & & \\
\hline 229 & tennis racket & 32.18 & 40.23 & 16.85 & 22.47 & 49.15 & 55.93 & & \\
\hline 230 & thimble & 39.08 & 50.57 & 22.47 & 23.60 & 71.55 & 86.21 & & \\
\hline 231 & thumb & 31.03 & 44.83 & 22.47 & 29.21 & 46.55 & 57.76 & & \\
\hline 232 & tie & 53.57 & 63.10 & 39.36 & 50.00 & 83.62 & 97.41 & 80.72 & 98.80 \\
\hline 233 & tiger & 23.81 & 23.81 & 27.66 & 31.91 & 43.97 & 46.55 & & \\
\hline 234 & toaster & 8.05 & 8.05 & 11.24 & 11.24 & 1.72 & 1.72 & & \\
\hline 235 & toe & 0.00 & 0.00 & 0.00 & 0.00 & & & & \\
\hline 236 & tomato & 67.86 & 67.86 & 46.81 & 46.81 & 87.93 & 88.79 & & \\
\hline 237 & toothbrush & 98.81 & 98.81 & 95.74 & 95.74 & 99.15 & 99.15 & & \\
\hline 238 & top & 4.60 & 6.90 & 6.74 & 6.74 & 64.66 & 70.69 & & \\
\hline 239 & traffic light & 11.49 & 12.64 & 4.49 & 4.49 & 7.63 & 8.47 & & \\
\hline 240 & train & 1.15 & 1.15 & 1.12 & 1.12 & 24.14 & 27.59 & & \\
\hline 241 & tree & 100.00 & 100.00 & 98.88 & 100.00 & 90.68 & 99.15 & & \\
\hline 242 & truck & 93.10 & 100.00 & 95.51 & 100.00 & 91.38 & 99.14 & & \\
\hline 243 & trumpet & 98.85 & 100.00 & 98.88 & 98.88 & 98.31 & 100.00 & 100.00 & 100.00 \\
\hline 244 & turtle & 100.00 & 100.00 & 98.88 & 98.88 & 100.00 & 100.00 & & \\
\hline 245 & umbrella & 100.00 & 100.00 & 97.75 & 100.00 & 96.61 & 100.00 & & \\
\hline 246 & vase & 98.81 & 100.00 & 94.68 & 95.74 & 95.69 & 99.14 & & \\
\hline 247 & vest & 2.38 & 44.05 & 2.13 & 34.04 & 0.00 & 62.07 & & \\
\hline 248 & violin & 80.46 & 82.76 & 74.16 & 74.16 & 70.34 & 72.03 & & \\
\hline 249 & wagon & 11.90 & 91.67 & 1.06 & 64.89 & 1.72 & 95.69 & 4.82 & 92.77 \\
\hline 250 & watch & 64.37 & 83.91 & 53.93 & 82.02 & 68.64 & 84.75 & 57.83 & 75.90 \\
\hline 251 & watering can & 98.85 & 98.85 & 95.51 & 97.75 & 97.46 & 98.31 & 98.80 & 100.00 \\
\hline 252 & watermelon & 4.60 & 8.05 & 0.00 & 7.87 & 2.54 & 11.02 & & \\
\hline 253 & well & 0.00 & 0.00 & 1.06 & 1.06 & 33.62 & 34.48 & 98.80 & 98.80 \\
\hline 254 & wheel & 0.00 & 1.15 & 0.00 & 0.00 & 0.00 & 0.00 & 79.52 & 100.00 \\
\hline
\end{tabular}


Table 2 (continued)

\begin{tabular}{|c|c|c|c|c|c|c|c|c|c|}
\hline \multirow[t]{2}{*}{ No } & \multirow[t]{2}{*}{ Name } & \multicolumn{2}{|c|}{ Silhouettes } & \multicolumn{2}{|l|}{ Outlines } & \multicolumn{2}{|c|}{ Inverted silhouettes } & \multicolumn{2}{|c|}{ New silhouettes } \\
\hline & & $\begin{array}{l}\% \text { exact } \\
\text { name }\end{array}$ & $\begin{array}{l}\% \text { correct } \\
\text { concept }\end{array}$ & $\begin{array}{l}\% \text { exact } \\
\text { name }\end{array}$ & $\begin{array}{l}\% \text { correct } \\
\text { concept }\end{array}$ & $\begin{array}{l}\% \text { exact } \\
\text { name }\end{array}$ & $\begin{array}{l}\% \text { correct } \\
\text { concept }\end{array}$ & $\begin{array}{l}\% \text { exact } \\
\text { name }\end{array}$ & $\begin{array}{l}\% \text { correct } \\
\text { concept }\end{array}$ \\
\hline 255 & whistle & 15.48 & 16.67 & 22.34 & 24.47 & 62.71 & 72.03 & 63.86 & 78.31 \\
\hline 256 & windmill & 39.29 & 95.24 & 60.64 & 100.00 & 51.72 & 100.00 & & \\
\hline 257 & window & 0.00 & 0.00 & 0.00 & 0.00 & & & & \\
\hline 258 & wineglass & 34.48 & 98.85 & 43.82 & 100.00 & 80.51 & 100.00 & & \\
\hline 259 & wrench & 13.79 & 70.11 & 17.98 & 67.42 & 27.97 & 79.66 & 19.28 & 95.18 \\
\hline 260 & zebra & 1.15 & 2.30 & 0.00 & 0.00 & 0.00 & 0.00 & & \\
\hline \multirow[t]{7}{*}{ Exp. 1} & average & 53.21 & 64.70 & 51.79 & 61.85 & & & & \\
\hline & $\mathrm{SD}$ & 38.55 & 39.76 & 38.79 & 39.61 & & & & \\
\hline & Q0 & 0.00 & 0.00 & 0.00 & 0.00 & & & & \\
\hline & Q1 & 9.84 & 17.56 & 8.99 & 15.90 & & & & \\
\hline & Q2 & 59.05 & 85.71 & 57.94 & 77.06 & & & & \\
\hline & Q3 & 93.10 & 98.85 & 93.26 & 98.88 & & & & \\
\hline & Q4 & 100.00 & 100.00 & 100.00 & 100.00 & & & & \\
\hline \multirow[t]{7}{*}{ Exp. 2} & average & 55.04 & 67.76 & 53.54 & 64.60 & 60.45 & 76.51 & & \\
\hline & $\mathrm{SD}$ & 36.93 & 37.50 & 37.20 & 37.57 & 33.93 & 32.65 & & \\
\hline & Q0 & 0.00 & 0.00 & 0.00 & 0.00 & 0.00 & 0.00 & & \\
\hline & Q1 & 15.21 & 35.63 & 14.75 & 27.66 & 27.78 & 61.64 & & \\
\hline & Q2 & 60.71 & 87.36 & 59.55 & 77.66 & 70.34 & 93.22 & & \\
\hline & Q3 & 92.41 & 98.85 & 92.55 & 98.37 & 91.38 & 99.15 & & \\
\hline & Q4 & 100.00 & 100.00 & 100.00 & 100.00 & 100.00 & 100.00 & & \\
\hline \multirow[t]{7}{*}{ Exp. 3} & average & 44.25 & 60.62 & 44.13 & 59.49 & & & 71.56 & 96.08 \\
\hline & $\mathrm{SD}$ & 38.83 & 42.31 & 36.28 & 39.06 & & & 28.64 & 6.39 \\
\hline & Q0 & 0.00 & 0.00 & 0.00 & 0.00 & & & 3.61 & 75.90 \\
\hline & Q1 & 2.38 & 5.75 & 5.32 & 14.25 & & & 48.80 & 93.80 \\
\hline & Q2 & 41.38 & 85.71 & 43.82 & 75.28 & & & 83.13 & 98.80 \\
\hline & Q3 & 79.31 & 97.70 & 76.50 & 97.81 & & & 95.18 & 100.00 \\
\hline & Q4 & 100.00 & 100.00 & 98.94 & 100.00 & & & 100.00 & 100.00 \\
\hline
\end{tabular}




\section{PERTEPTION}

VOLUME 372008

www.perceptionweb.com

Conditions of use. This article may be downloaded from the Perception website for personal research by members of subscribing organisations. Authors are entitled to distribute their own article (in printed form or by e-mail) to up to 50 people. This PDF may not be placed on any website (or other online distribution system) without permission of the publisher. 